\title{
Chemistry in Second Life
} Andrew SID Lang*1 and Jean-Claude Bradley²

\author{
Address: ${ }^{1}$ Oral Roberts University, Department of Computer Science and Mathematics, 7777 S Lewis Ave, Tulsa, OK 74171, USA and ${ }^{2}$ Drexel \\ University, Department of Chemistry, 32nd and Chestnut Streets, Philadelphia, PA 19104, USA \\ Email: Andrew SID Lang* - alang@oru.edu; Jean-Claude Bradley - bradlejc@drexel.edu \\ * Corresponding author
}

Published: 23 October 2009

Chemistry Central Journal 2009, 3:14 doi:10.1 186/1752-153X-3-14

This article is available from: http://journal.chemistrycentral.com/content/3/1/14

(C) 2009 Lang et al
Received: 9 July 2009

Accepted: 23 October 2009

\begin{abstract}
This review will focus on the current level on chemistry research, education, and visualization possible within the multi-user virtual environment of Second Life. We discuss how Second Life has been used as a platform for the interactive and collaborative visualization of data from molecules and proteins to spectra and experimental data. We then review how these visualizations can be scripted for immersive educational activities and real-life collaborative research. We also discuss the benefits of the social networking affordances of Second Life for both chemists and chemistry students.
\end{abstract}

\section{Introduction}

With over 80,000 simultaneous users on at any given time, Second Life has emerged as the most popular non game-based 3D virtual world [1]. Users interact with the environment and with each other in the form of avatars, usually lifelike representations of people or animals. Since users are empowered to create objects and environments of their choosing, almost every aspect of real life has been replicated in Second Life. Of course, since virtual worlds do not necessarily suffer the same limitations as reality, creative adaptations abound. Science is no exception and many exhibits in Second Life can be found depicting scientific content [2].

Chemistry presents some special challenges and opportunities for a platform like Second Life. Full use of 3D space is a real asset, since an understanding of the shape of molecules and orbitals is essential for chemists. We will show how such representations can be made in Second Life and how these have been applied to educational activities. Chemical data can also benefit from use of 3D space and some examples of interactive exhibits will be detailed. Finally, the social networking aspect of Second Life sets this virtual platform aside from others and this will be demonstrated.

This review does not attempt to exhaustively compare Second Life with other currently available technologies and platforms that perform similar operations. It is also not our intent to compare specific educational outcomes from using Second Life compared to alternative approaches or platforms. The targeted readers of this review are educators, students and other chemistry professionals who are curious about ways of using Second Life for chemistry related projects. We do however briefly note that there are several packages [3] available to display molecules in 3D on the web, such as, Jmol [4] and RasMol [5]; and even methods to embed interactive 3D molecular structures into PDF documents[6]. Representations of the dynamics of chemical reactions in 3D are available from browserbased applications; an excellent example is the Mol4D tutorial site [7]. Finally, social networking sites where chemists can interact on the web are multiplying very quickly [8]. 


\section{Visualization Molecules}

Second Life provides an environment to interact with molecules in their full $3 \mathrm{D}$ representations. It is only recently that it has been possible to easily render molecules with realistic conformations. Our molecule rezzer, named Orac [9], is a tool that anyone can use to easily create molecules without having to painstakingly link prims together or learn Linden Scripting Language - the scripting language of Second Life. The Orac molecule rezzer interacts with the user via the chat interface; you tell Orac the molecule that you want and he builds it for you. Orac accepts any SMILES [10], InChi [11] or InChiKey [12] via chat. Orac then queries web-services at ChemSpider (Inchi web-service provided by Antony Williams) and Indiana (smi23d web-service provided by David Wild) which dynamically calculate and return the minimized 3D structure; Orac then rezzes the molecule in Second Life, see Figures 1 and 2.

The molecules that Orac makes can be manipulated in many ways. You can easily change the position, size and orientation; you can save the molecules to your inventory for later retrieval, make multiple copies and even distribute them to other users. Also, with a little scripting, you can make the molecules interact with users and even each other.

\section{Reactions}

Using Second Life, it is possible to render chemical reactions in full 3D [13]. By scripting the atoms and bonds of molecules to respond to chat, users can step through a reaction mechanism by simply typing "next" and "back." As the user commands the molecules he sees bonds twist, break, and re-form as the atoms move to their new positions in each fully minimized intermediate structure. Figure 3 shows snapshots of the reaction of benzaldehyde with 5-methylfurfurylamine to form an imine and water. Each intermediate in the reaction has been minimized (using smi23d) to show a realistic conformation. Large changes in geometry are easily appreciated within the 3D environment, something that is not easily represented in $2 \mathrm{D}$ renderings on paper.

\section{Docking}

Simple non-rigorous rigid docking, via hydrogen bond contact points, can easily be implemented using Second Life's built in scripting language. We scripted an example from real-life anti-malarial research [14], so that when a user clicks on the docked molecule it jumps out of the binding pocket to a random location but same orientation. It then self-docks back into the binding pocket of the targeted enzyme (enoyl reductase in this case) by minimizing the simulated H-bond interaction energy. The four hydrogen-bonding interactions between the molecules and the atoms involved are tagged in green, something

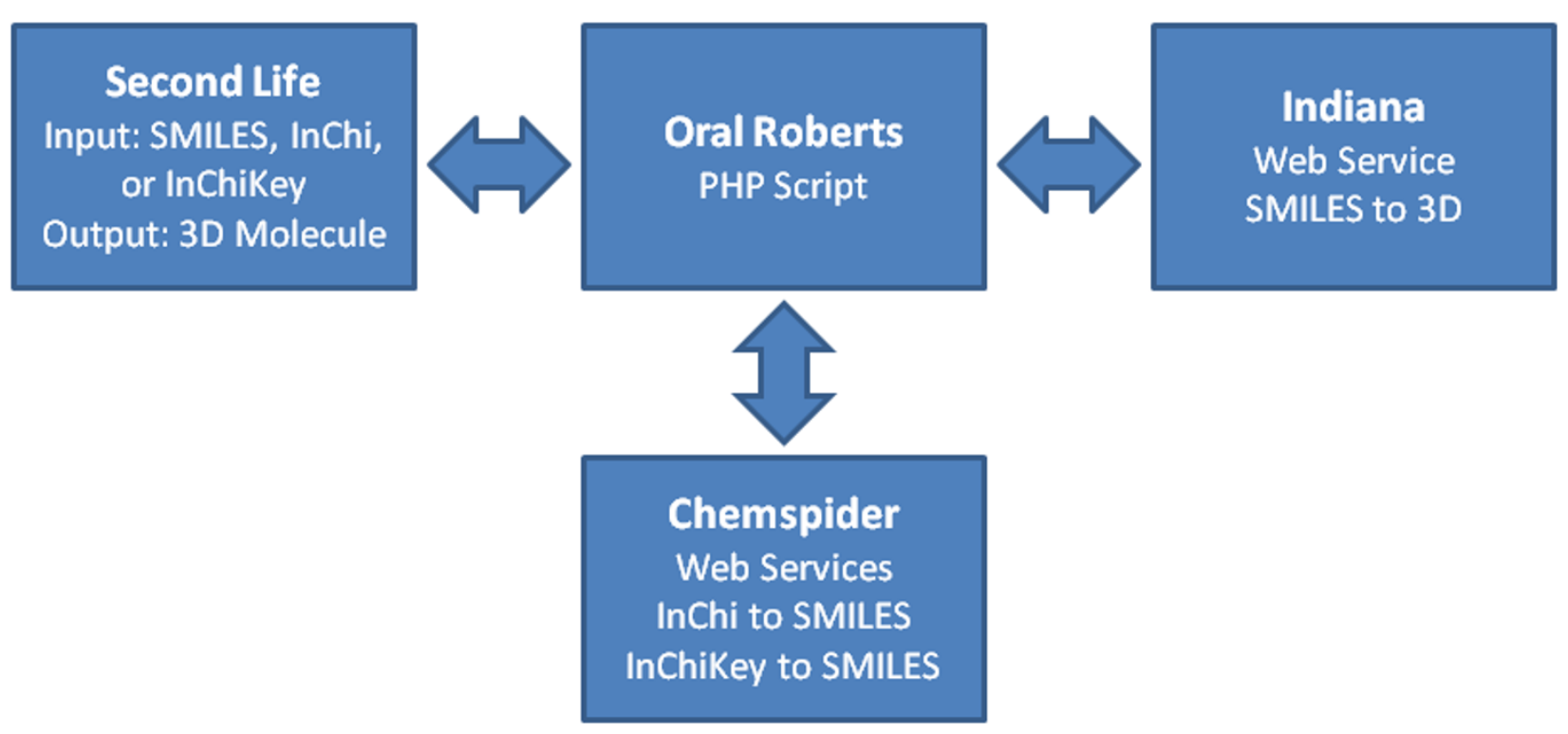

Figure I

Orac uses freely-available web services to dynamically calculate and display 3D molecular data. 


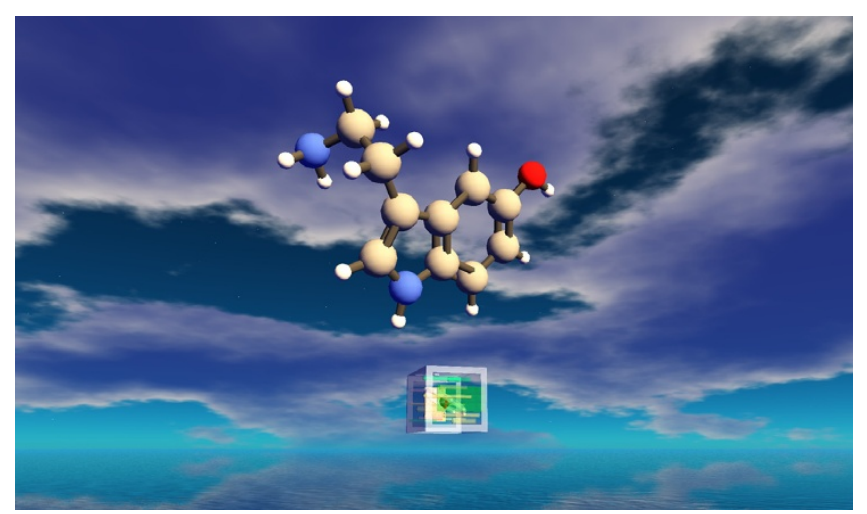

Figure 2

Orac and serotonin.

that is common in stand-alone docking visualization applications such as Jmol and Pymol, see Figure 4[15].

To achieve a more realistic docking simulation, a docking web-service could be used; and together with human interaction more efficient and sometimes better results (by avoiding local minima), over computer-only docking, can be achieved [16].

\section{Peptides}

A good example of how Second Life can be used as a platform for enhancing education through visualization has been provided by Joan Slonczewski of Kenyon College who has created "Amino World" to help students identify amino acid R-groups in peptides [17]. Amino World consists of five peptides each composed of four amino acid residues, see Figure 5.

The peptides of Amino World are fully interactive, complete with extensive information available on notecards that users can save to their inventories, and by clicking on the peptide tower controller or the molecule itself you can highlight different structures such as the peptide backbone and the different R-groups. The R-groups can be made to identify themselves and copies can be taken and examined by users.
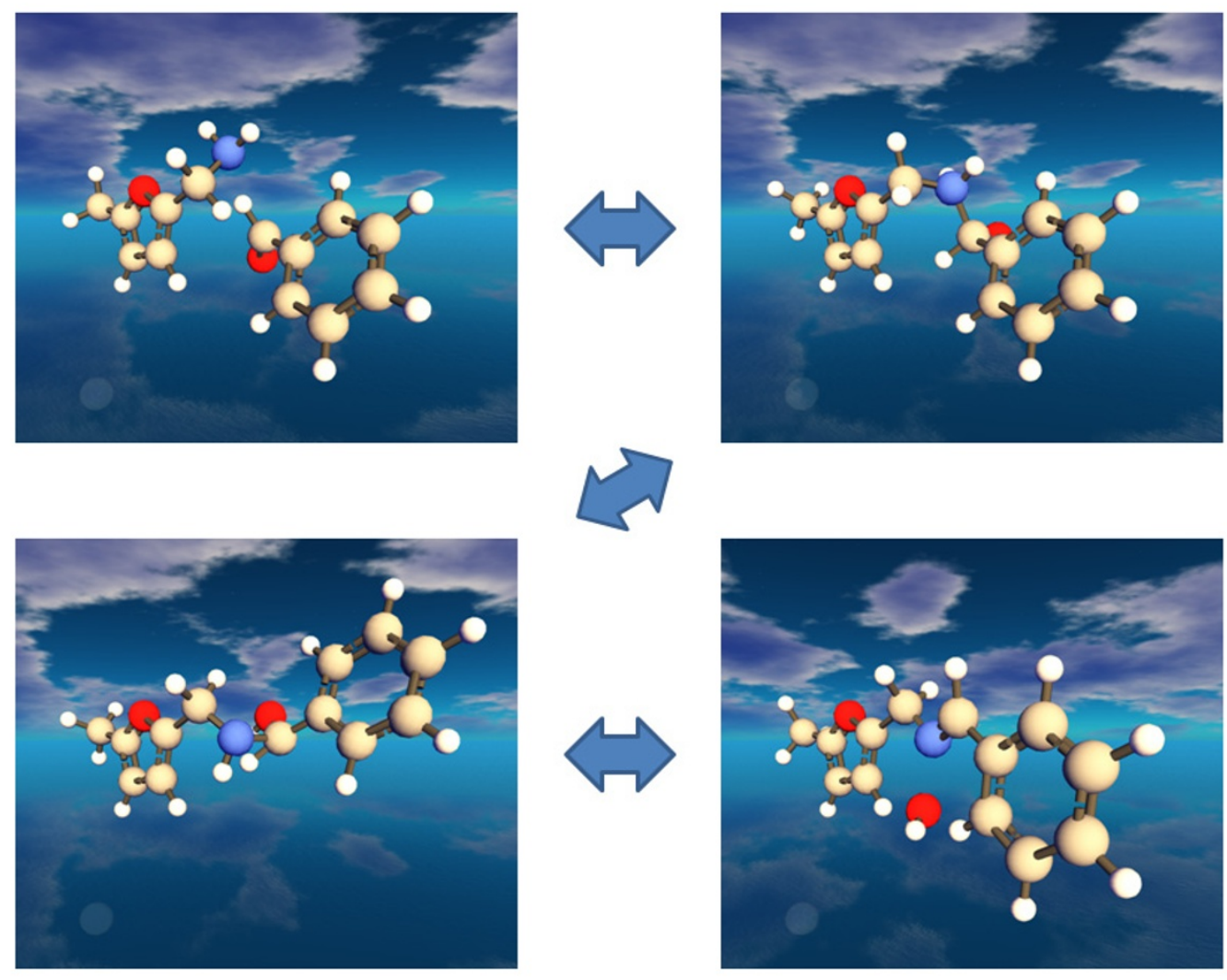

\section{Figure 3}

Snapshots of each step in a user-controllable reaction mechanism simulation. 

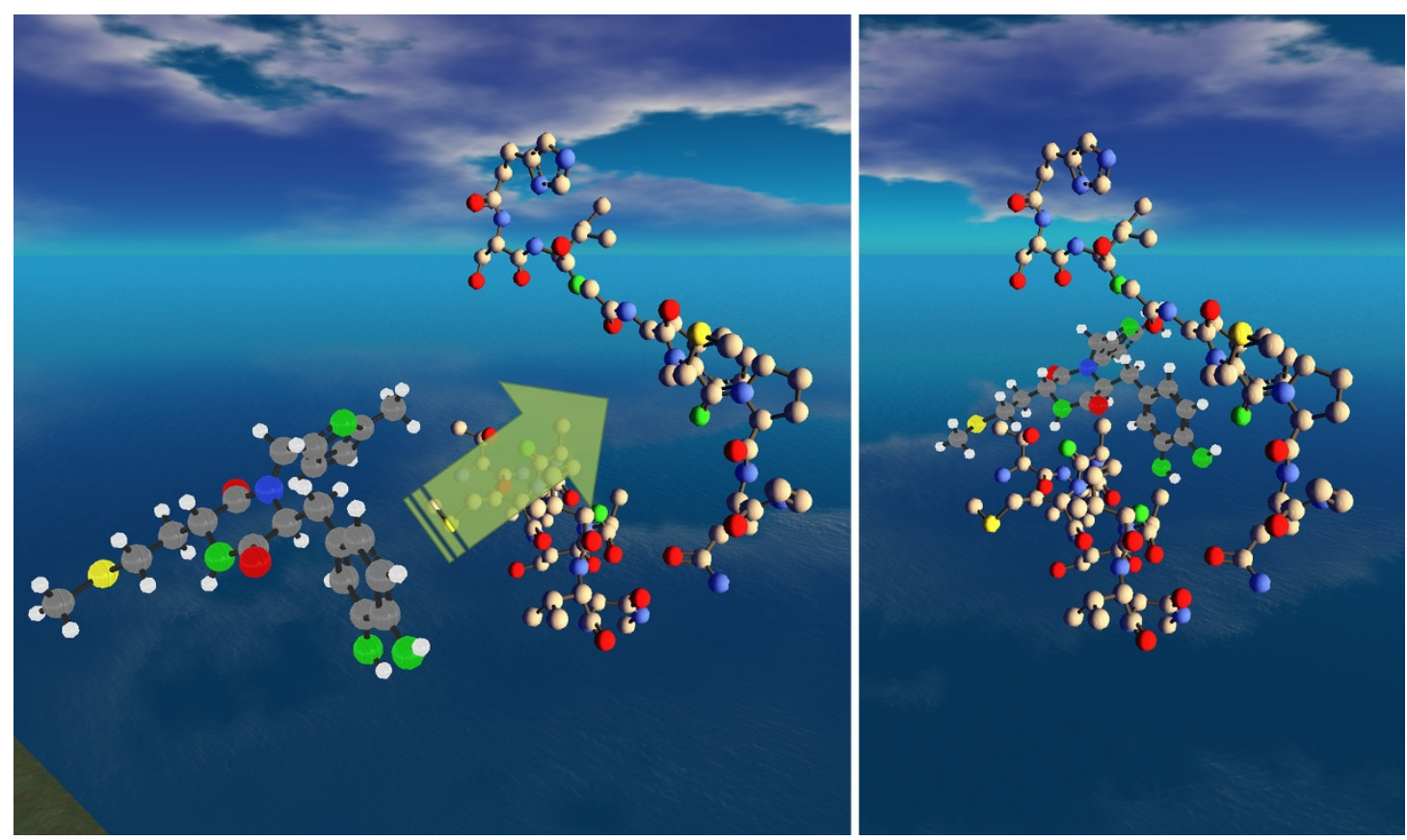

Figure 4

Molecule docking in Second Life.

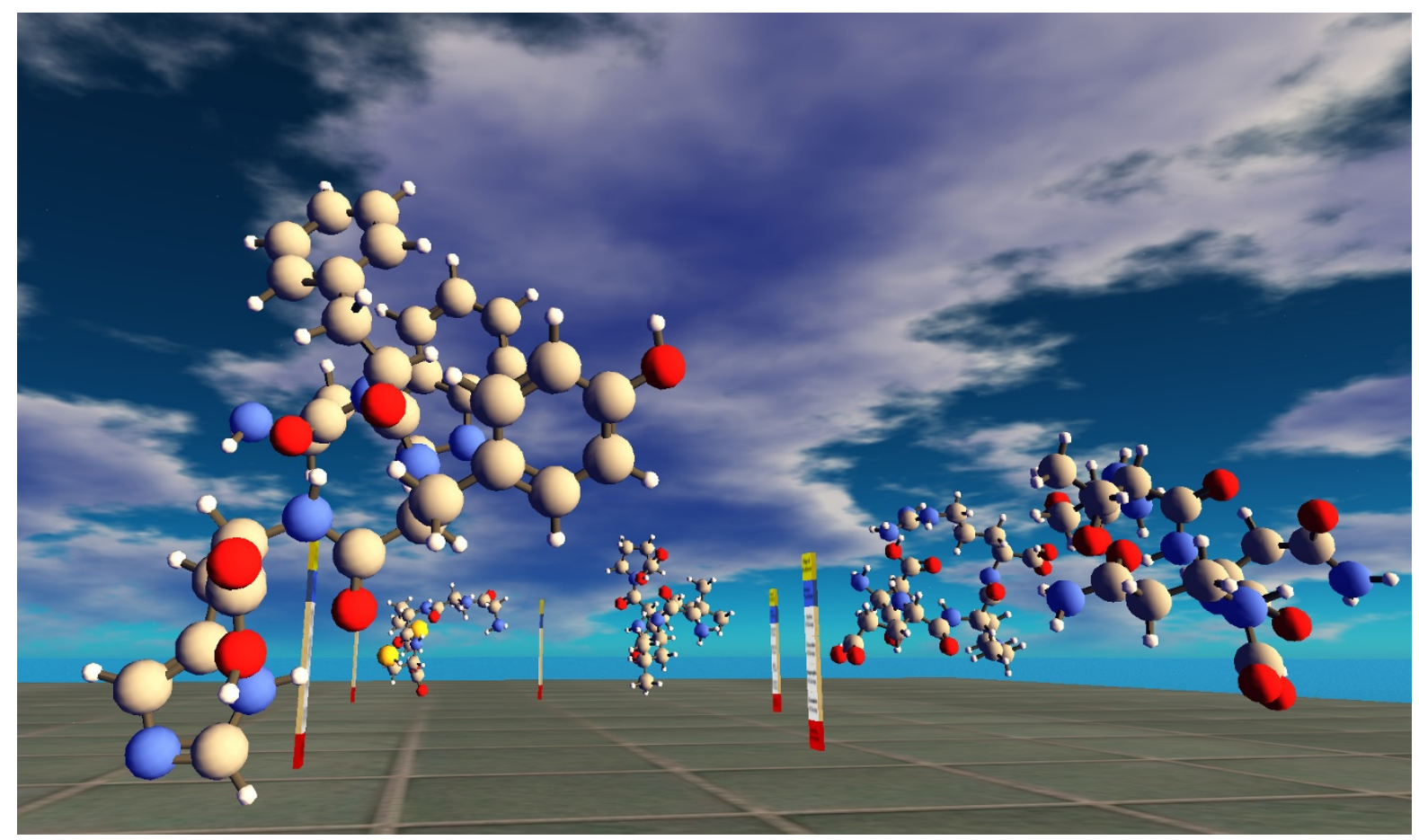

Figure 5

Amino World. 


\section{Proteins}

Second Life has a few built-in limitations that currently makes the rendering of large stick-and-ball molecules impractical. For example, there is a limit to the number of atoms that can be linked together to form a single molecule. Practically this limit is around 120 atoms for most molecules. It is possible to have Orac rez molecules up to the prim limit $(15,000$ prims on a single sim), but such molecules would be one-time structures and you would not be able to save them to your inventory (as a single molecule). Also, with such a large structure you wouldn't be able to build anything else. Several solutions to these limitations have been developed. Peter Miller at the University of Liverpool has developed a 'Protein Rezzing Toolkit,' based on code originally written by Troy McConaghy, which allows for the creation and packaging of proteins up to the simulator prim limit [18]. The toolkit allows users to create and manipulate simple protein structures from PDB files, which are available from a freely accessible database [19]. The molecule once packaged and re-rezzed will respond to touch by displaying the residue number, type and amino acid (for the atom). The molecule also responds to user chat commands allowing users to search for and display sheets, helices, and particular amino acids, see Figure 6.

The protein rezzing toolkit gives users the ability to manage large protein structures in Second Life. These structures however are still prim intensive so we have also developed a sculpted protein web-service. This web-serv- ice takes any PDB file and calculates the macromolecular solvent-accessible surface of the protein using methods similar to those developed by Greer and Bush [20]. This surface is then rendered as a 'Sculpt Map' - a 128 by 128 pixel image of the projected surface data with $\mathrm{x}, \mathrm{y}, \mathrm{z}$ coordinates represented via the three channel RGB format. This image can then be uploaded into Second Life and rendered as a 'Sculpted Prim.' The same web-service also creates texture maps colored based on closest amino acid residues, charge, and polarity, that allows users to texture their proteins accordingly; see Figures 6 and 7.

Another protein rezzer is Monolith[21] scripted by Erich Bremer of Stony Brook University. Like the Protein Rezzing Toolkit, Monolith reads and parses PDB files. Monolith then rezzes the atoms of the structure in $3 \mathrm{D}$. This makes it prim intensive but it rezzes structures relatively quickly - it can rez a $3000+$ atom protein in under a minute. The atoms rezzed by Monolith are interactive, allowing the user to set labels, change colors based on residue name/number, set transparency of atoms interactively, and to display subsets of atoms. This makes Monolith a potentially useful tool for dynamic collaborative discussions, though unlike Orac, Hiro's Molecule Rezzer [9], or the Protein Rezzing Toolkit [18], it is currently not Open Source or freely available. Also, unlike Orac, which can make any structure, Monolith resembles the Protein Rezzing Toolkit in that it is limited to structures stored in PDB format.

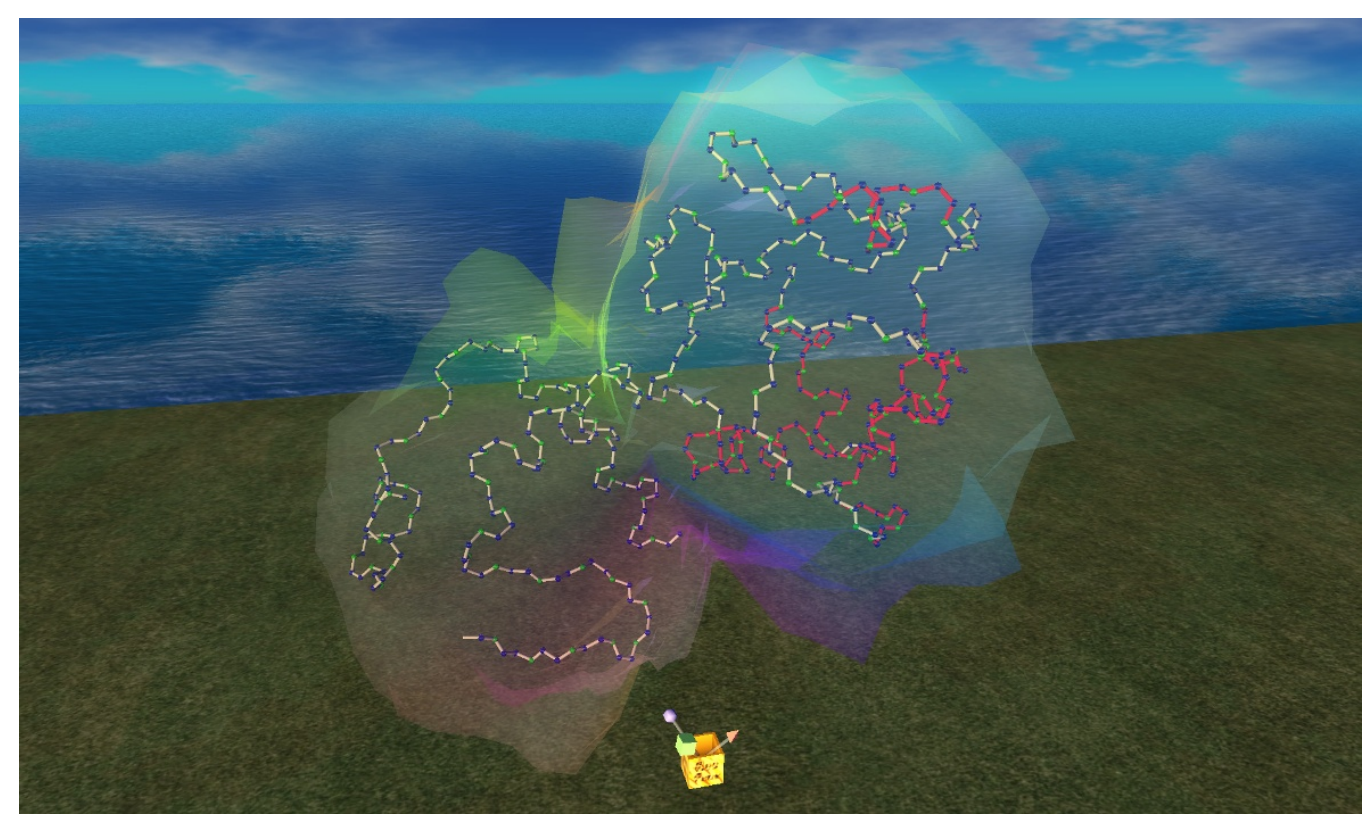

\section{Figure 6}

A protein (3cyt) rezzed using the protein rezzing toolkit enveloped in a single-prim sculpted protein. 


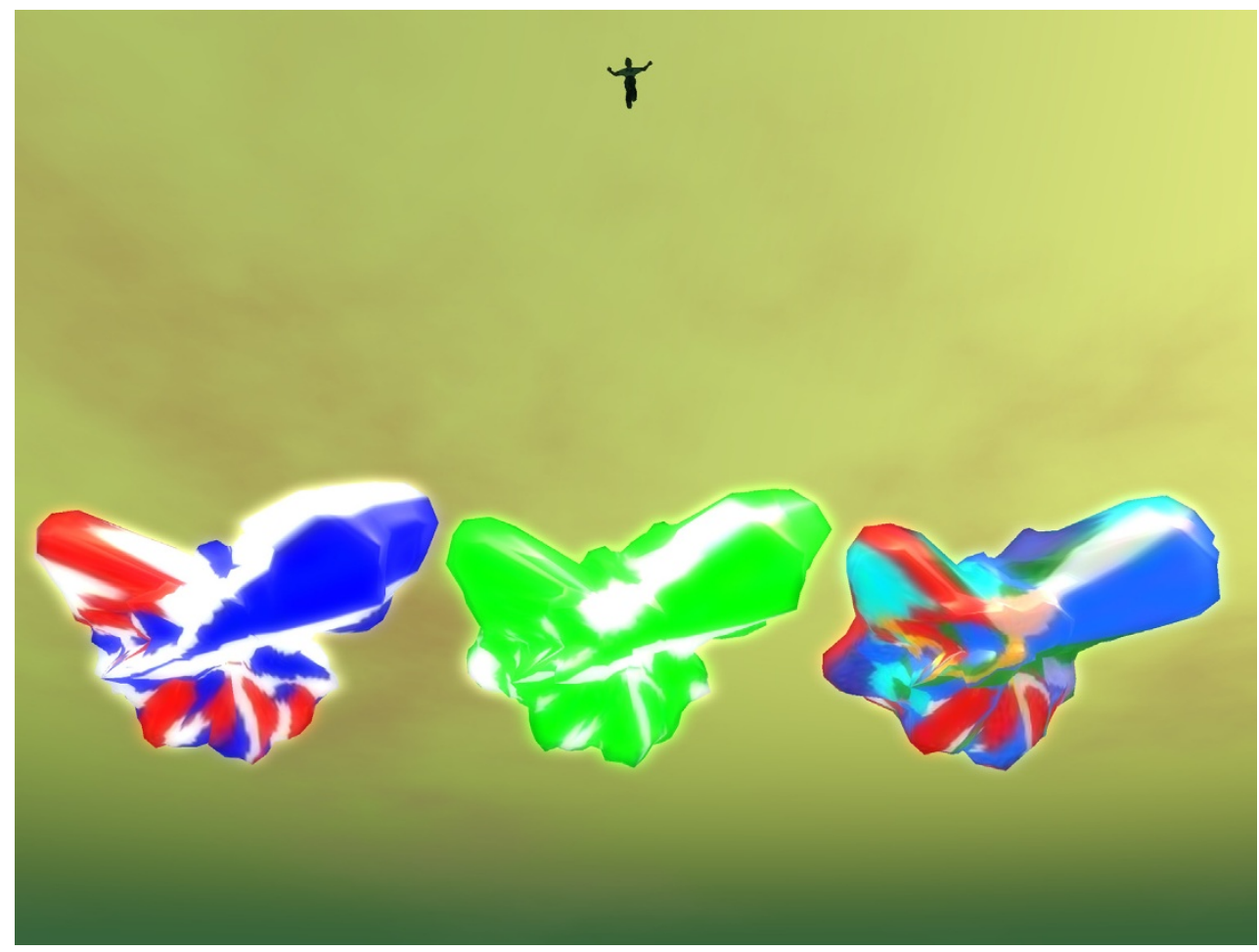

\section{Figure 7}

A sculpted protein (falcipain-2) colored from left to right by amino acid charge, polarity, and amino acid residue respectively.

Paul Bourke of the University of Western Australia has also done innovative work in evaluating Second Life for remote collaboration and visualization, including chemistry visualization. His work includes examples of immersive crystal structure visualization, including Hershfield surfaces, using preprocessed spherical projections, a useful low prim visualization technique [22].

\section{Data Visualization \\ Spectra}

Second Life continues to improve its interoperability with the Web and therefore its usefulness as a platform for interacting with all forms of media, including scientific data. One thing that is now possible is the ability to dynamically create images on any server and then have that image appear on a prim in Second Life for all to see. We have used this ability to build an interactive spectrum viewer [23]. The viewer interacts with users via chat and responds to commands such as "zoom [range]," "back" and "reset." By typing "zoom" with a specified range of values you can expand any area of the spectrum. The integral value is also calculated and displayed on the resulting image. The viewer works by querying a PHP script which parses a specified JCAMP-DX spectrum file, calculates the integral for the specified range, and uses the Google Chart
API to create and return to Second Life an image of the spectrum, see Figures 8 and 9 .

The particular spectrum shown can be changed from within Second Life by simply changing the Media URL to point to the appropriate spectrum file. Displaying spectra in Second Life has advantages over currently available web-based viewers: In addition to the inherent collaborative nature of Second Life, it is easier to control focus, has the integral value, and can be used in conjunction with other chemistry visualization tools, see Figure 10 and The Spectral Game below.

\section{Solubility}

As part of a research project to synthesize anti-malarial agents using the Ugi reaction [24], we are collecting solubility data of Ugi reagents and products in non-aqueous solvents. This non-aqueous solubility data, produced via crowdsourcing [25], is stored as open data in a Google spreadsheet. Using the Google spreadsheets data API we can display this data in Second Life, see Figures 11 and 12.

Our Ugi solubility explorer is a data visualization tool that allows users to select the four components of the Ugi reaction (an aldehyde, an amine, an isonitrile, and a carboxy- 


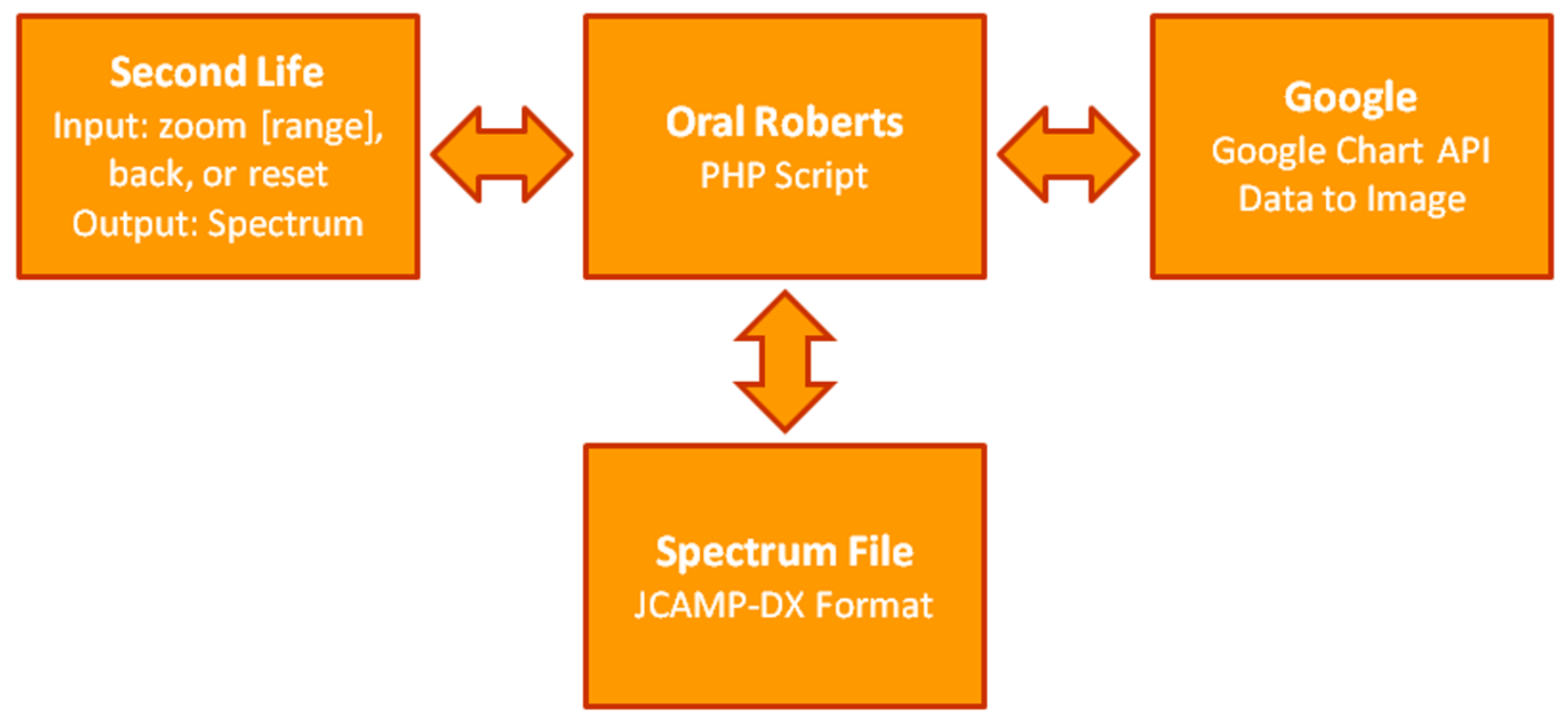

Figure 8

The spectrum viewer uses the Google chart API to dynamically create spectrum images.

lic acid) and view the solubility data for each compound in various solvents in a $3 \mathrm{D}$ bar chart. Clicking on a bar opens a web-page showing the dynamic solubility data for each experiment with links to the lab notebook, see Figure 13.

Another way to view the solubility data as a whole is through interactive descriptor chemical spaces [26], see Figure 14[27]. The interactive chemical space is a real-time 5-dimensional visualization of the solubility data with the three spatial directions corresponding to CDK [28] descriptors of the user's choice. The fourth and fifth dimensions are point-size which is proportional to the solubility concentration and the color of the point indicating the functionality of the solute, respectively. By clicking on the data point in Second Life, you again can access the solubility data for each experiment, see Figure 13. One of the advantages of viewing the data in Second Life over traditional two-dimensional chemical space visualization is the third molecular descriptor which can reveal patterns in the data that often get hidden in twodimensional points [29].

The solubility explorer and 5-dimensional chemical space rezzer allows us to explore the data in real-time to find target solvents for particular combinations of Ugi reactants and analyze the chemical space for solubility trends. It also allows us to easily visualize regions of the data, seeing where the data is sparse, and guiding further research.

\section{Teaching Applications \\ Quizzes}

Using a collection of tiles (bitmap images) that are true or false in any context has proved to be a versatile means of creating chemistry quizzes on various platforms for undergraduate organic chemistry quizzes taught at Drexel university. This collection was first used as part of the EduFrag project [30] in the first person shooter game Unreal Tournament, in versions both with and without weapons. The images were used as doors to pass through. Correct images on the doors led further in the game maze or provided rewards (health, weapons, strategic positioning, etc.) while incorrect doors led to negative outcomes such as losing a life or starting the maze again, see Figure 15. In the non-weapons version of the game, such quizzes were often used in the form of races where the first student to complete the maze won a prize (typically a molecular model kit or a textbook) [31].

When porting over to Second Life, the format of the quizzes was altered to minimize the use of prims, building elements that are limited in number for each building area. In one implementation, obelisks were used to identify the location of quizzes [32]. Upon clicking an obelisk 4 tiles appear, including only one that is correct, see Figure 16. Clicking on this correct tile generates another set of four tiles and advances the student in the quiz. Clicking on an incorrect tile resets the quiz. By assigning each participating student one obelisk and ensuring that everyone starts 


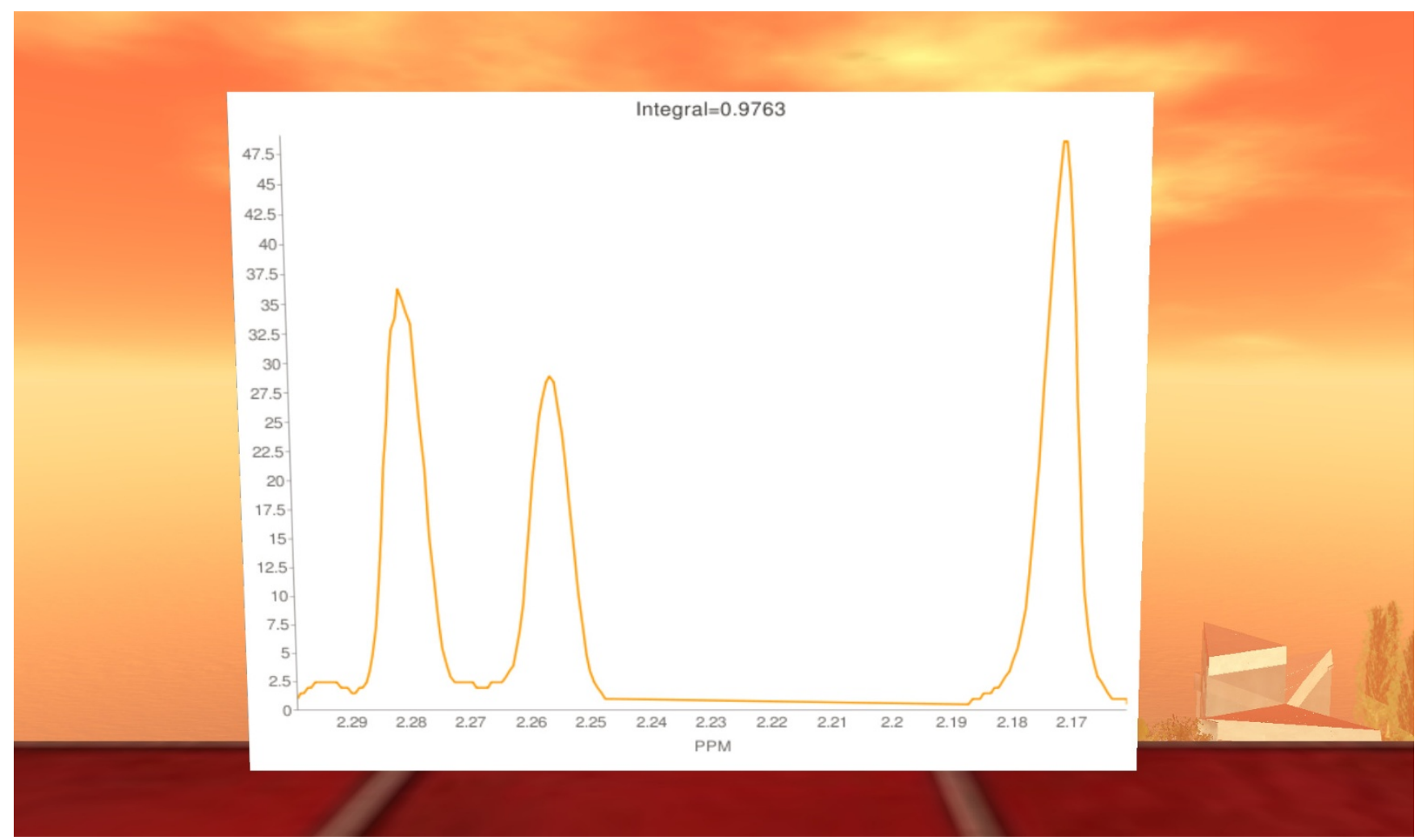

Figure 9

Interactive spectrum viewer.

at the same time, races can be held in the same way that they had been in Unreal Tournament.

In the most recent implementation of these quizzes, content was ported over to a web interface. The resulting ChemTiles game [32] is now more accessible to everyone, since neither Unreal Tournament nor Second Life need to be installed. However, as will be detailed below, the social aspect of Second Life is absent in the web version. The web version maintains a high score list, so contests do not need to be run in real time in the form of races. During an implementation of the game in the spring of 2009 at Drexel University, students were given about a week to achieve the high score. Students in the class only competed against each other for prizes by signing up under the Drexel group. However, the game is open to anyone in the world to try.

The default is to get a random collection of tiles covering all categories, with only one correct in the mix but each category can be practiced separately simply by selecting from a drop-down menu. At the beginning of the game two tiles, one correct and one incorrect are shown, and the user is asked to click on the tile that is correct. If the user selects the correct tile, then they proceed to the next set of tiles and the process is repeated. The game becomes increasingly difficult with the number of tiles increasing, to a maximum of six. Additionally, when a player reaches a score of forty, rounds also become timed, see Figure 17, and the player must select an answer before the countdown expires. The amount of time a player gets decreases as rounds progress to a minimum of ten seconds, making the game a challenge, even for experts.

The insertion of new content in the form of bitmap images was streamlined in this version by uploading all the tiles to a Flickr group [33] and tagging each image according to its category, such as Lewis structures, chirality, etc. The tiles uploaded to Flickr automatically become part of the game via an API provided by Flickr. Hosting the tiles on a Flickr group allows for the crowdsourcing of questions.

\section{Spectral Game}

Since NMR spectroscopy is taught in CHEM242 (Organic Chemistry II) at Drexel, the Spectral Game was evaluated in this class during the Winter 2009 term [34]. Students were given the option of using the resource in Second Life in order to better prepare for tests. The instructor used the game during workshops with individual students to teach 


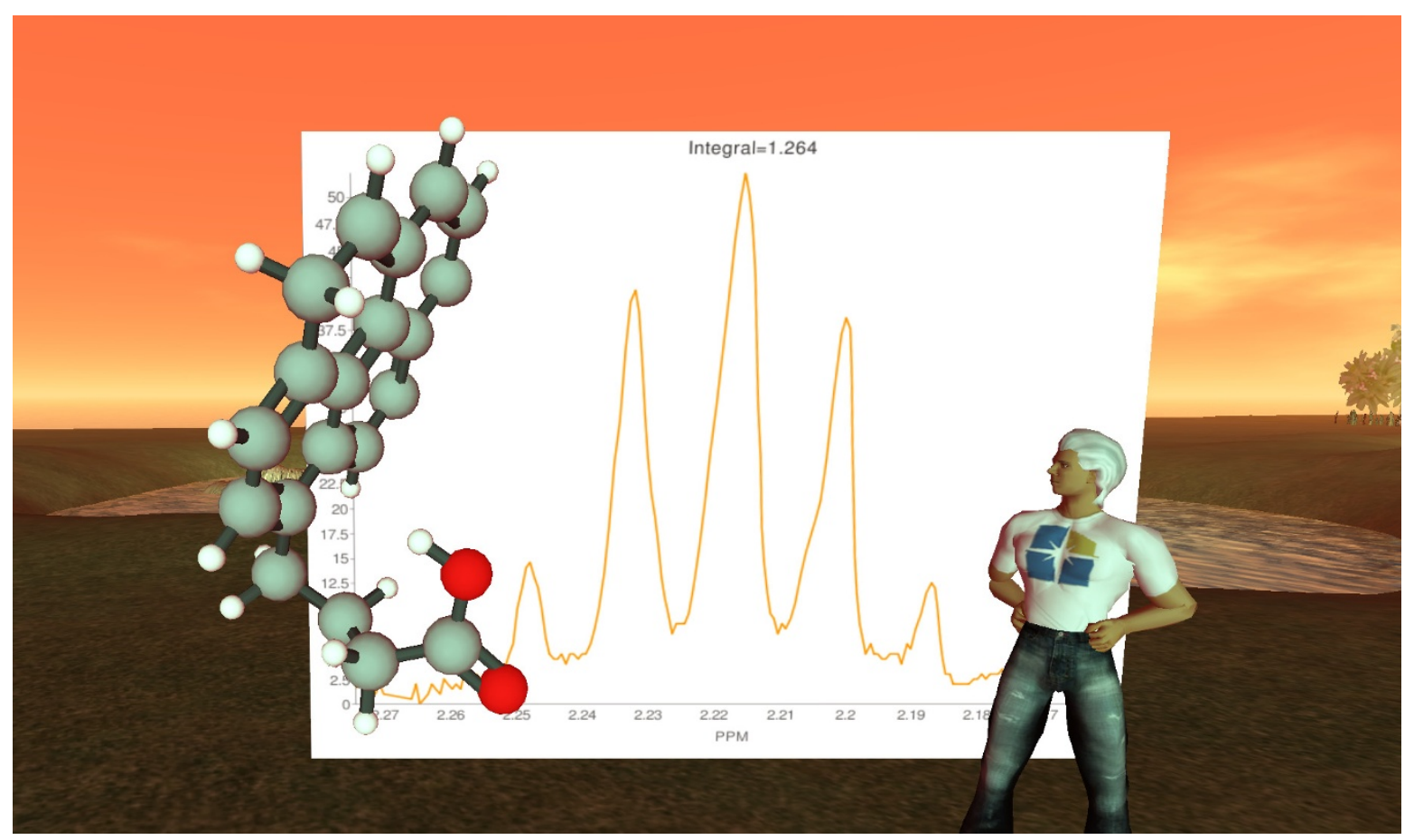

Figure 10

I-Pyrenebutanoic acid together with its NMR spectrum.

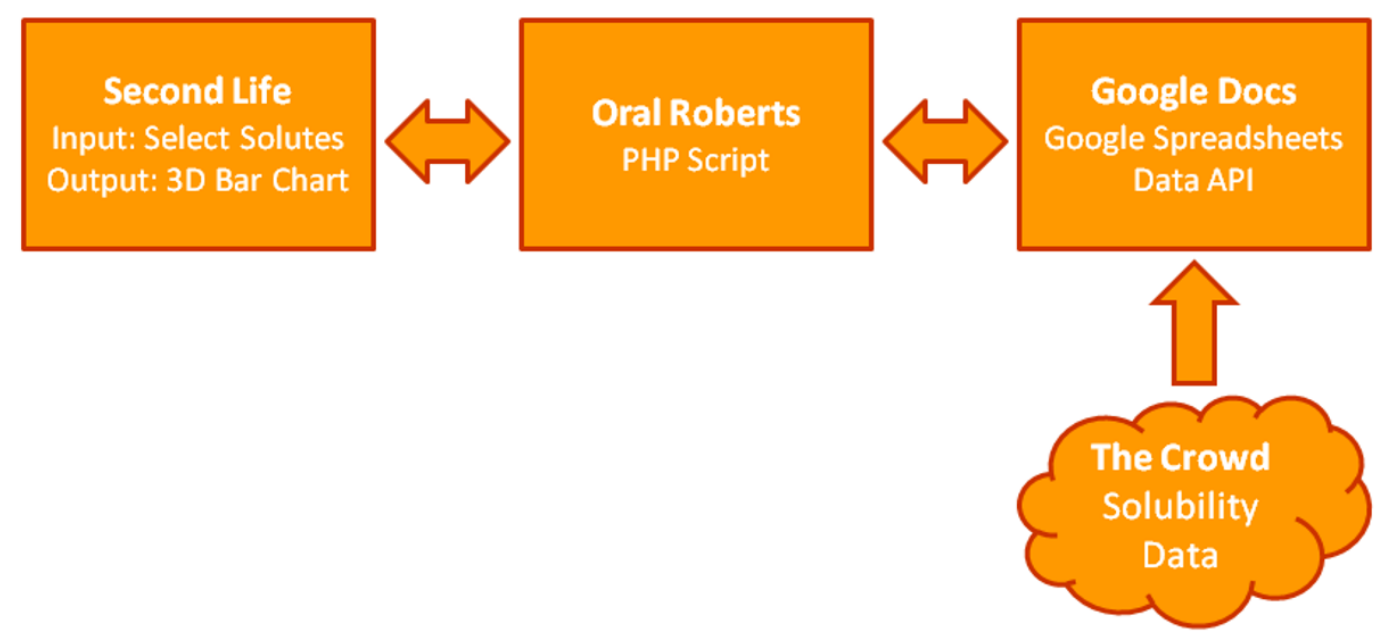

Figure I I

The 3D solubility data explorer displays data stored in a Google spreadsheet. 


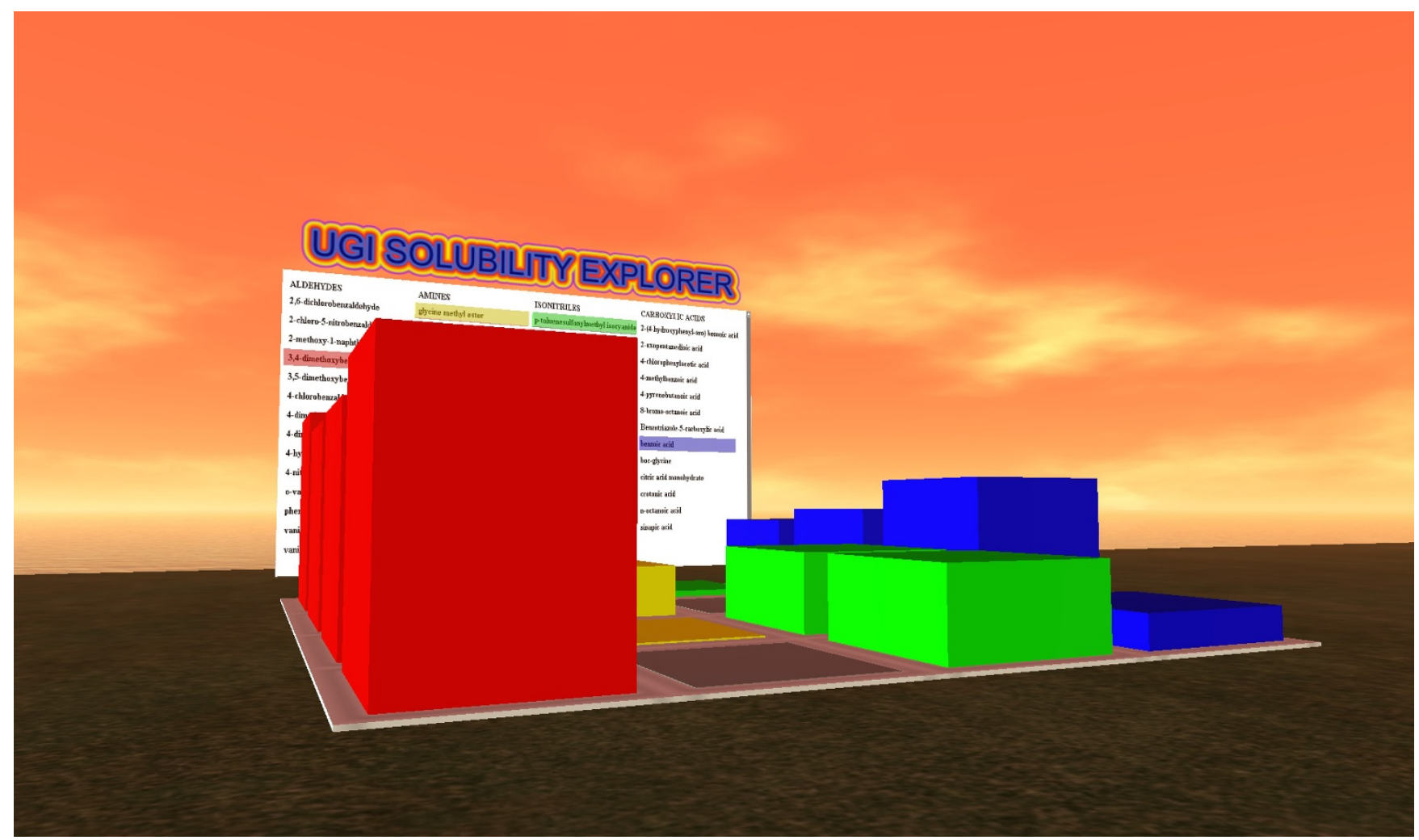

Figure 12

Ugi reaction solubility explorer.

them concepts as they appeared in the NMR spectra, see Figure 18.

The presentation of molecules in $3 \mathrm{D}$ was especially helpful for bridged cyclic structures, which are difficult to imagine correctly using $2 \mathrm{D}$ representations. The chat interface with the spectral display board was easy to master to zoom into desired regions. With the implementation of the web version of the Spectral Game [35], most students migrated to that version since it did not require downloading software or learning a new interface. For students who are physically present in a workshop the web version is probably more convenient, whereas teachers who have most students participate remotely may find significant advantage in using the Second Life version.

\section{Student Exhibits}

In addition to teacher generated content, Second Life provides a rich environment for student projects. Students at Drexel University were given the option of creating exhibits for up to $2 \%$ extra credit on their final grade. This relatively small reward usually affords on the order of $5 \%$ participation, which is useful for large undergraduate courses, where it would be impractical to have 200 students trained and guided within Second Life. Although some training is required, optimally in a face-to-face workshop environment, students are asked to use simple tools.

The Orac rezzer is an especially easy to use tool since students simply need to look up the SMILES code of a molecule of interest and pass the information to Orac via the chat interface. There are several easy ways to look up SMILES such as the ChemSpider database or the free chemical drawing package ChemSketch. Posters are also conveniently prepared by creating an image on PowerPoint or other similar software and uploading to Second Life. Poster boards are provided to students and they are shown a simple way to copy their images to boards. Some of the boards have the ability to open a browser window upon clicking. By combining posters and 3D molecules, students can quickly prepare exhibits of their choosing, relating to material learned in class, see Figure 19[36].

\section{Networking}

In addition to providing a rich environment for 3D exhibits, Second Life enjoys a vibrant community of scientists. Students can benefit from spending time in areas with scientific content simply for the people that they meet who happen to be interested in the same topics. In the spring 
Solubility of 4-nitrobenzaldehyde in acetonitrile

Number of Results: 5

Experiment Page or Citation

1. Maccarone, E; Perrini, G. Gazzetta Chimica Italiana vol 112 p 447 (1982) [pdf (8) ]

2. Maccarone, E; Perrini, G. Gazzetta Chimica Italiana vol 112 p 447 (1982) [pdf \& ] 4

3. http://onschallenge. wikispaces.com/Exp098

4. http://usefulchem wikispaces.com/exp212

5. http//usefulchem. wikispaces.com/exp 212

$\mathrm{n}=5$

mean $=1.1646$

standard deviation $=0.1834$

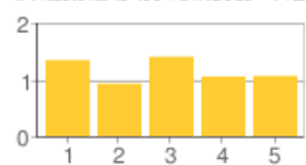

Concentration (M)

\section{Figure I 3}

Solubility of 4-nitrobenzaldehyde in acetonitrile.

2009 term, students at Drexel University taking introductory organic chemistry were asked to seek out and interview people on Second Life who are connected somehow to chemistry related fields. Another part of this extra credit assignment involved taking snapshots of areas in Second Life with chemistry content. A convenient way of identifying suitable people on Second Life involved identifying the creator of chemistry objects and contacting them by IM. FriendFeed, another social networking site was made the target of interviews for people involved with chemistry. The results of this assignment were aggregated on the class wiki [37] and highlight the richness of projects and networks of people working in the field. Such networking, impossible not so long ago, could prove crucial for students to identify opportunities in the course of their education and career.

\section{Research \\ Laboratory Information}

Web sites have now become a ubiquitous platform for sharing information about research projects. Second Life can be used in a similar way by making use of $3 \mathrm{D}$ exhibits. For example, a project involving the synthesis of antimalarial compounds [14] displays one of the molecules synthesized in the group and the target protein, see Figure 20. Posters give brief descriptions of the exhibit and load a web page with more information about each topic. Images of lab equipment and pictures of group members can be made available to provide more insight about a research group. As described below, the American Chem- ical Society Island had dedicated a portion of its space to house areas where chemists can showcase their research work.

\section{Conferences}

Given the ability to stream video into Second Life combined with the ease of converting PowerPoint presentations into a similar format in Second Life, many groups are exploiting the platform to host conferences, both fully virtual and mixed reality (with interaction between real life and second life venues). A notable example in chemistry involved the presentation of about 20 posters on ACS island in the Spring of 2008 [38], see Figure 21. Hosting conferences in Second Life is more cost effective for both hosts and attendees. It also alleviates the need to travel which saves time, money, and is beneficial to people with disabilities who may not be able to travel and scientists in developing countries who may not be able to afford to travel. Second Life conferences consequently have much smaller carbon footprints over real-life conferences. While Second Life conferences cannot give the full experience of a real-life conference, they have been shown to continue some of the benefits of real life conferences including effective teamworking, networking, collaboration, innovation, and socializing [39].

Chemistry content can also be found at more general conferences and special events covering the sciences most notably on the Elucian Islands Archipelago owned by Nature Publishing Group who host the Nature Podcast 


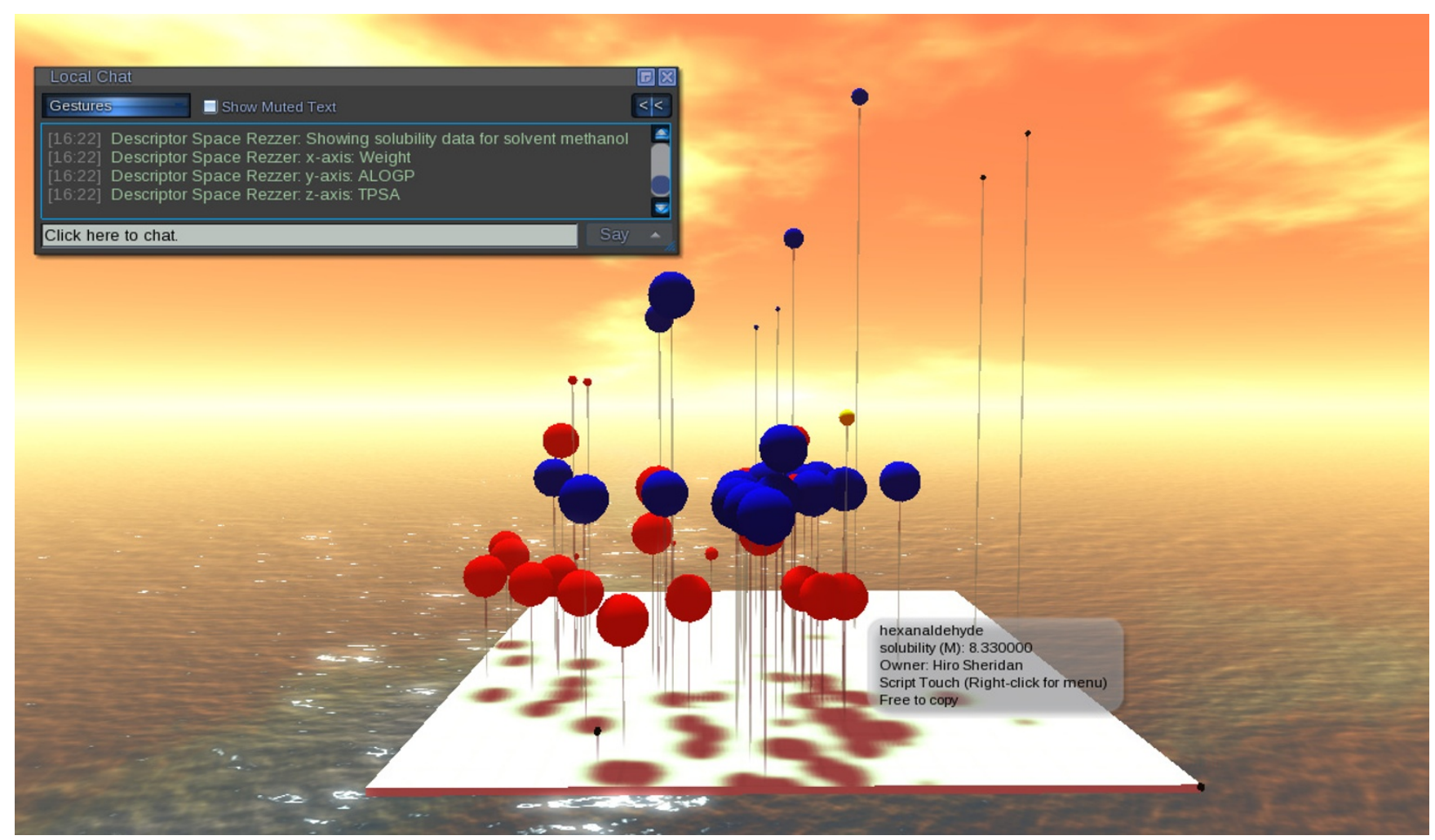

Figure 14

5-Dimensional interactive solubility data visualization. Originally appeared in [22].

[40] in Second Life and the Sci-Foo Lives On conference [41], as well as other conferences in science communication related events [42].

\section{Collaborations}

As mentioned above, one of the most useful attributes of Second Life is its ability to promote networking. For educators and researchers, this can turn out to be at least as valuable as leveraging the platform for the creation of $3 \mathrm{D}$ exhibits. By simply spending some time on Second Life to create content or assist students, one often accidentally meets people who may ultimately end up as collaborators at some point. People that one meets can be added to a friends list very easily by clicking on their avatar. Whenever one logs in the list of friends currently online is highlighted and any of these people can be contacted by IM or teleported over to interact with a group. The ease with which this can happen in Second Life enables rapid growth of contacts via friend-of-a-friend networks. The authors of this paper represent an excellent example of a collaboration originating from Second Life and evolving to include work in drug discovery, solubility and data visualization, both in Second Life [43] and on the bench [29].

\section{Islands with Chemistry Content ACS Island}

ACS Island is the Second Life home of the American Chemical Society [44]. The ACS uses the island for virtual poster sessions, held sometimes concurrently with its national meetings; special talks both technical and educational and is currently developing an outreach program for local sections. ACS Island also naturally has many exhibits relating to chemistry created by both the American Chemical Society and by "resident scientists" who are ACS members with virtual labs [45] on ACS Island. The exhibits on ACS Island include "Amino World," discussed above, an interactive chemical landmarks museum which houses interactive and animated displays explaining such things as nylon, DNA, and HIV; and a red-tide exhibit showing how farmland fertilizer and animal waste can exacerbate harmful algal blooms, see Figures 22 and 23.

The American Chemical Society also provides many free virtual items in its HQ building including amongst other things a molecule rezzer [9], a 3D periodic table [46], and clothing such as an ACS branded outfit consisting of a tshirt, lab coat, and safety goggles. 


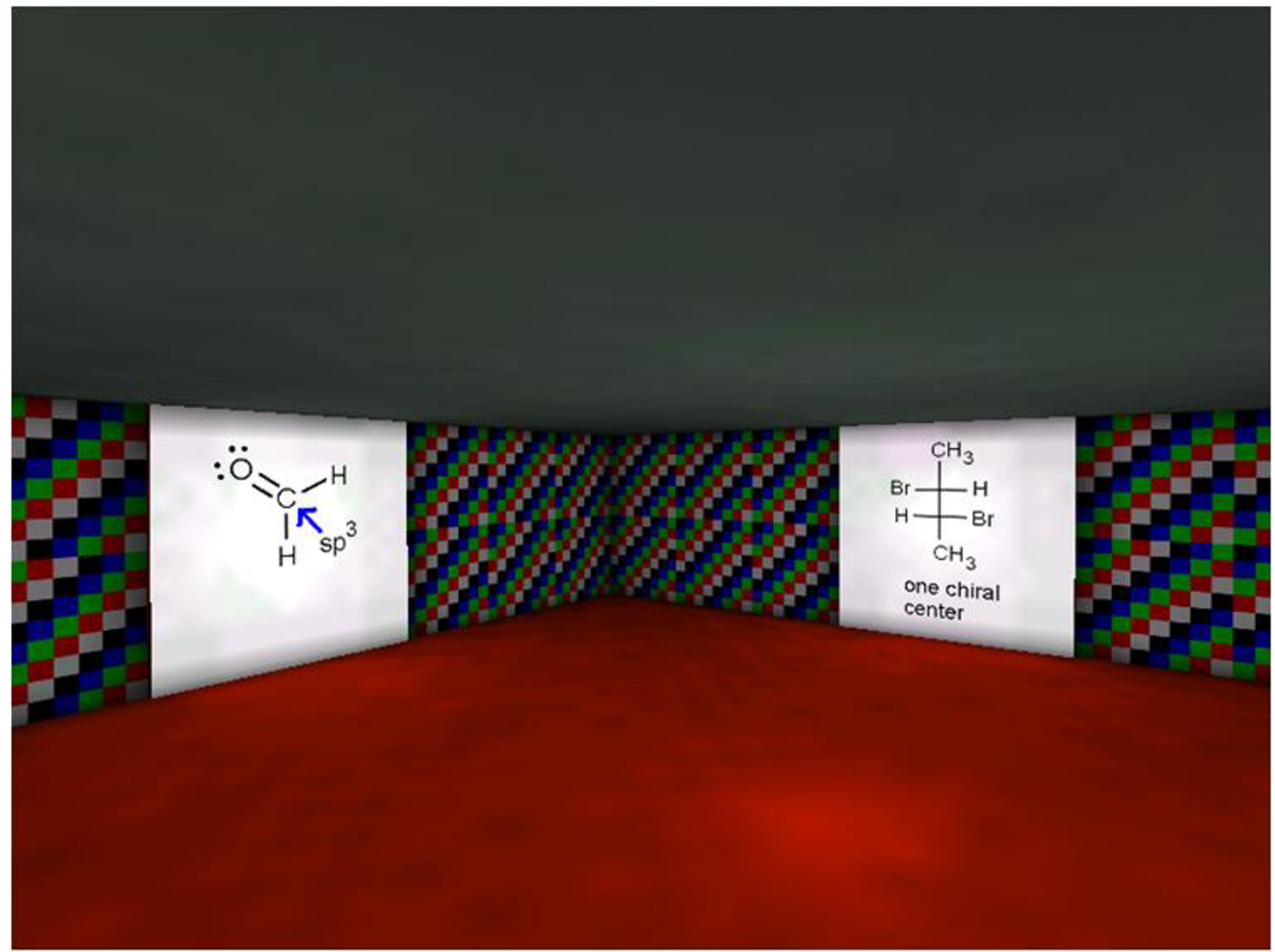

Figure 15

Unreal Tournament maze with organic chemistry content on doors.

\section{Drexel}

The northeast corner of Drexel Island [47], see Figure 24, houses chemistry content relating to organic chemistry courses and research from the Bradley research group. Many of the exhibits discussed in this article can be found there with some additional chemistry related content provided by Sigma-Aldrich.

\section{Elucian Islands}

Nature Publishing Group, the publisher of the journal Nature has several islands in Second Life known collectively as the Elucian Islands Archipelago [48]. Nature uses these islands to hold both mixed reality events and Second Life only events such as Sci-Foo Lives On [41]. Nature also hosts and displays chemistry-related exhibits including an interactive lab explaining atomic orbitals, hydrogen absorption spectra, and selection rules [49] and an interactive gallery of proteins (green fluorescent protein,
DNA helicase, etc.) created by David Reeves of Yeshiva University, see Figure 25.

\section{Conclusion}

This article represents a snapshot of some current chemistry related activities in Second Life. The open, immersive, and highly visual 3-dimensional platform combined with the ease of content creation and scripting makes Second Life a valuable tool for conducting chemistry research, education, and collaboration. As with many technological innovations, change can happen quickly. It is expected that chemistry's presence in Second Life will continue to expand in unexpected ways as more people join and bring their creativity to innovate in this virtual world.

\section{Glossary}

Avatar - A user's avatar or agent is a virtual representation of themselves inside Second Life. Chat - In Second Life 


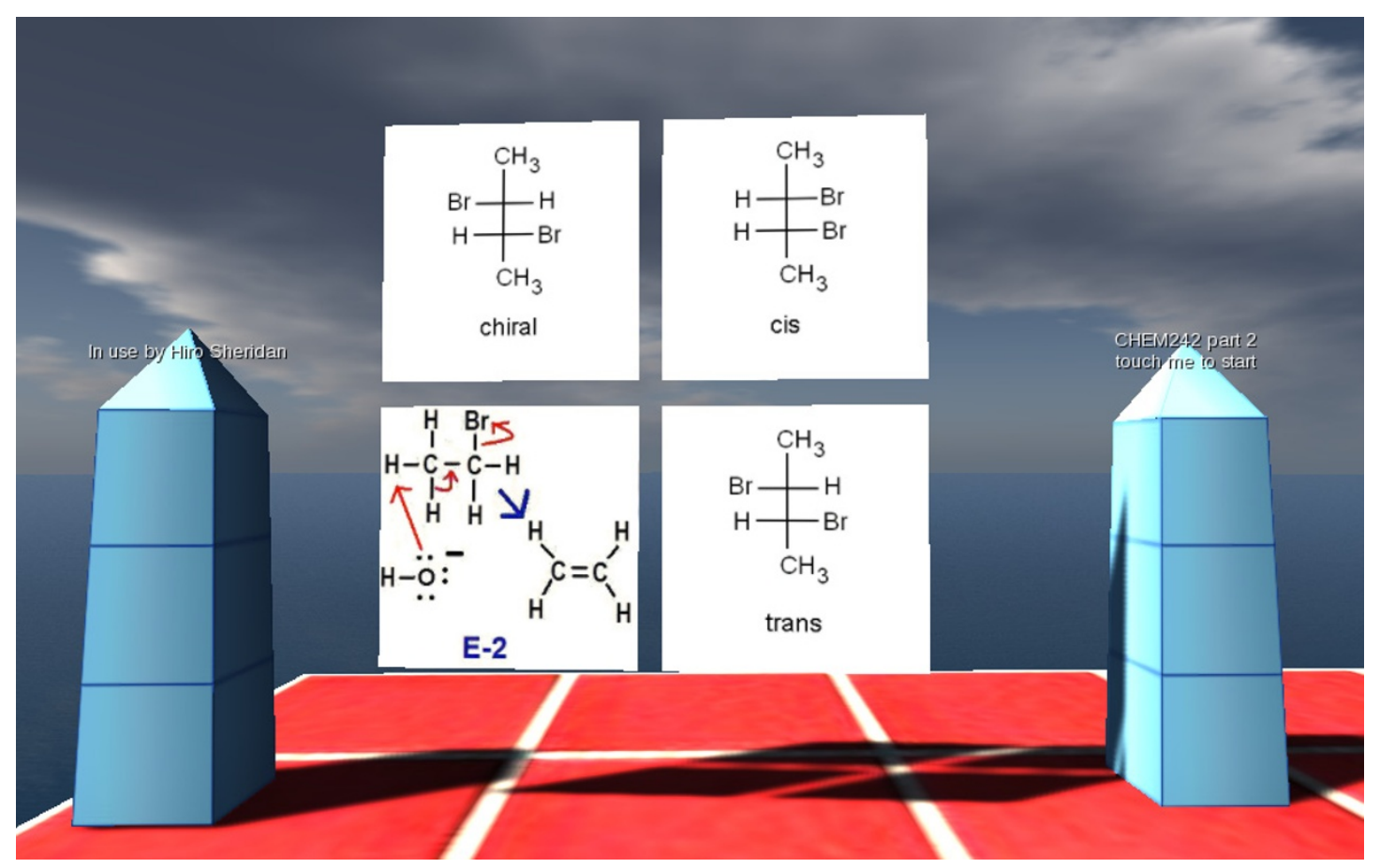

Figure 16

Quiz obelisk in Second Life showing 4 random quiz tiles that appear upon clicking.<smiles>[2H][PH3]</smiles><smiles>CC1CCCC(Br)C1</smiles>

3 products

(not counting enantiomers)

Correct. Your Current Score: 40

Click on the image that corresponds to correct chemistry. Game Over in 27 seconds.

Figure 17

The ChemTiles game.

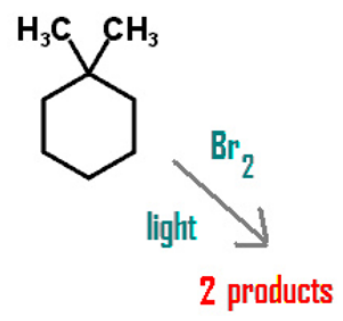

(not counting enantiomers)

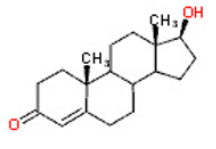

this molecule has

a vinyl ether

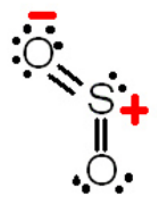

This is a correct

Lewis structure 


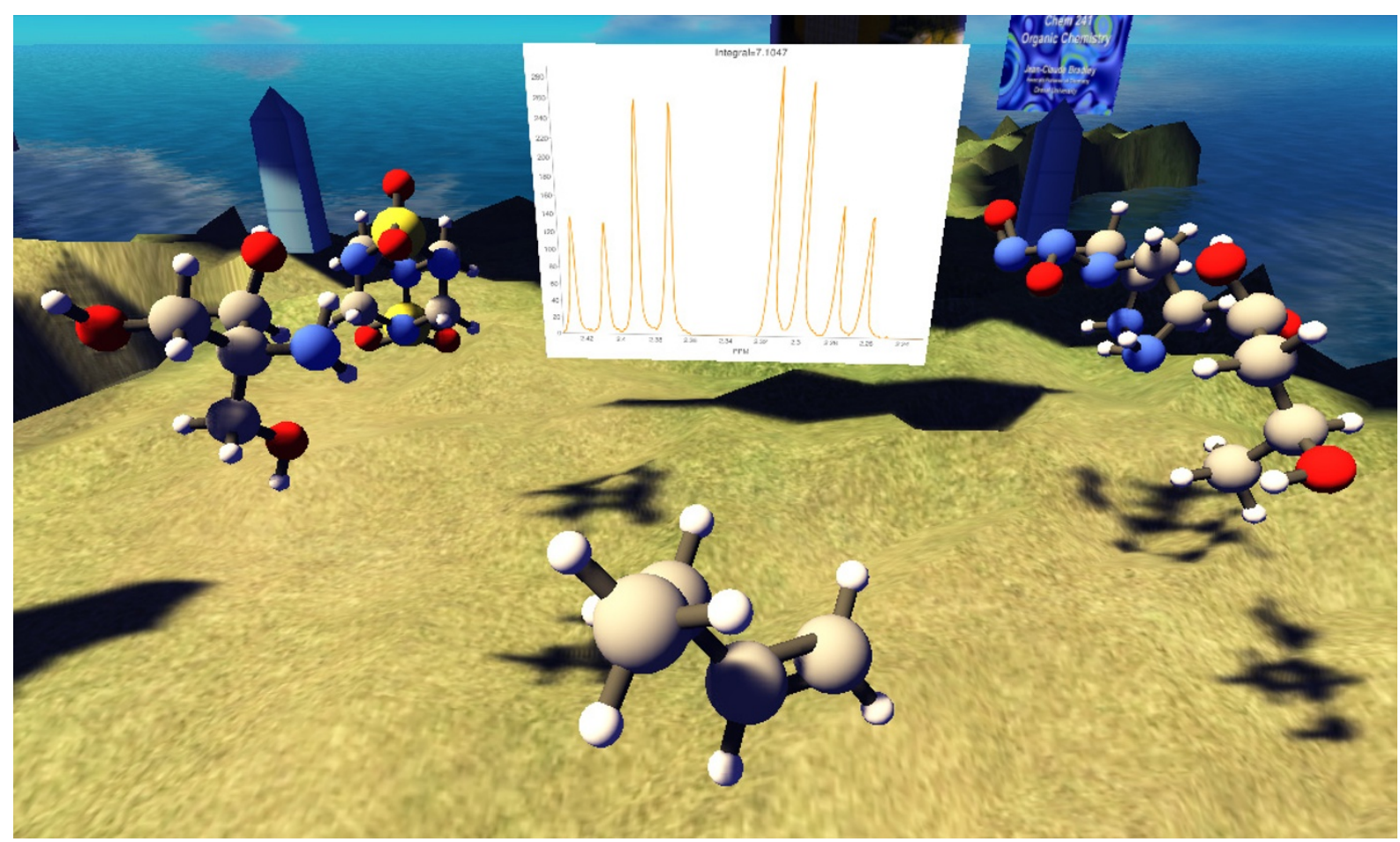

Figure 18

The Spectral Game in Second Life. Originally appeared in [29].

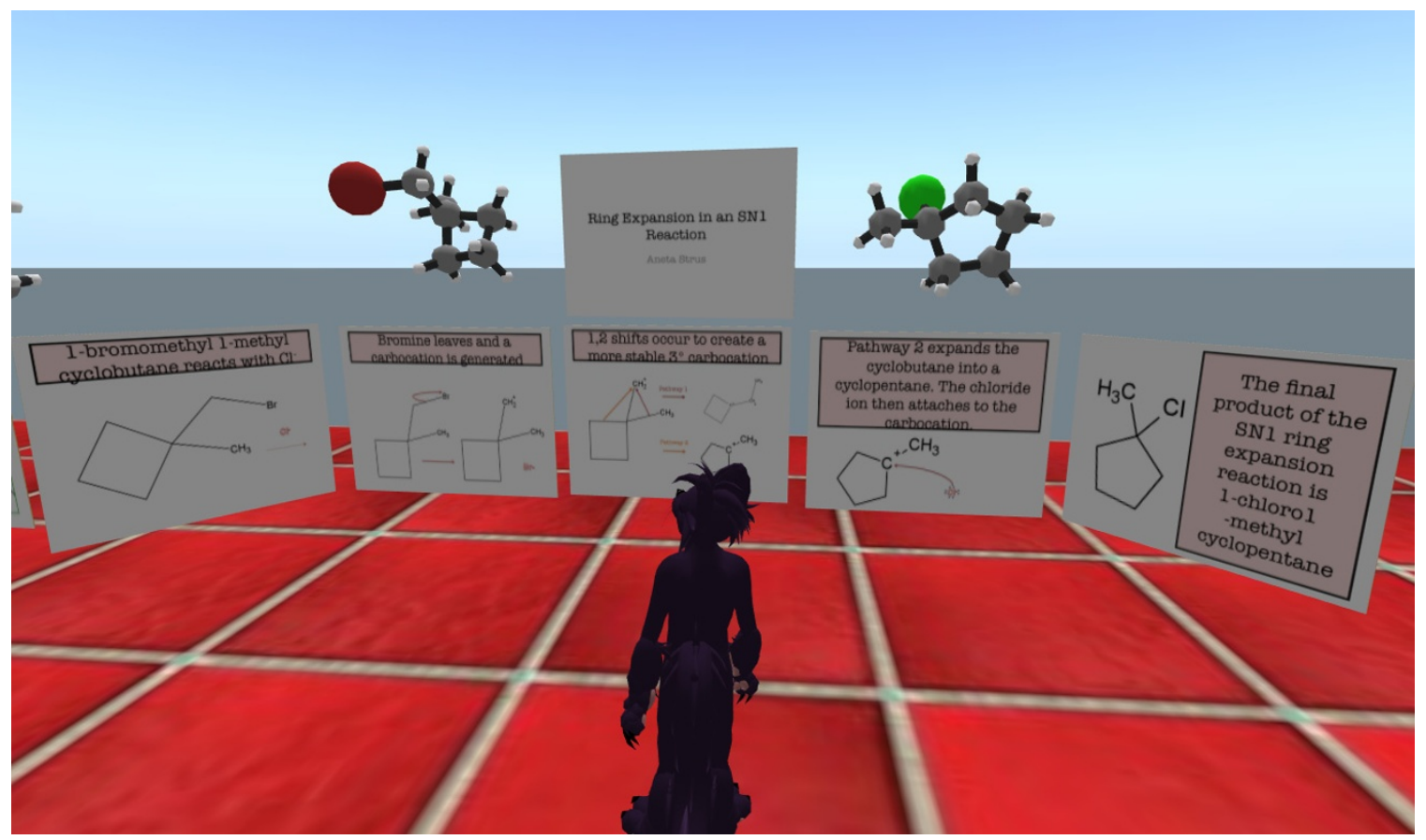

Figure 19

A student exhibit in Second Life. 


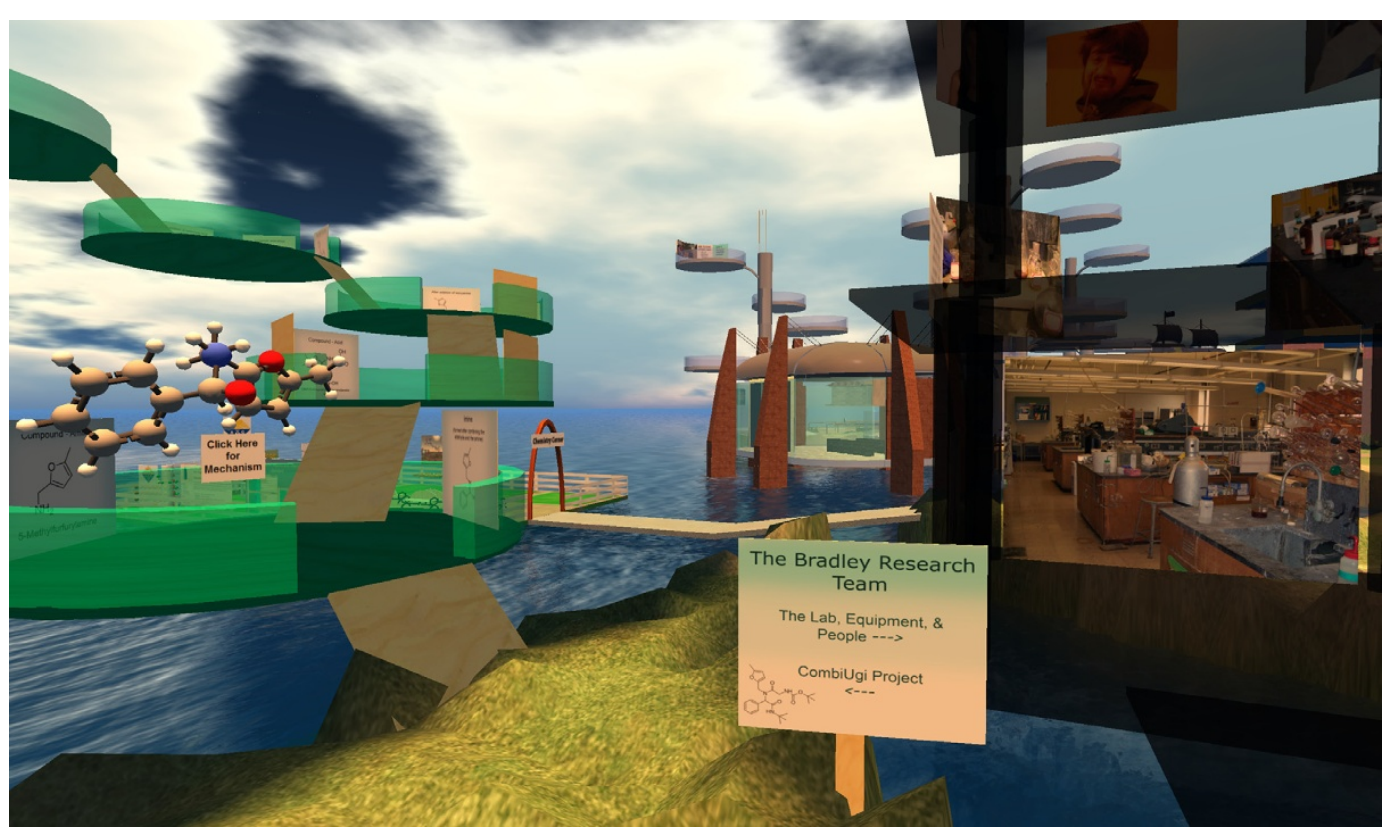

Figure 20

A section of the Bradley research lab showing pictures of the lab equipment on the right and 3D reaction mechanisms of one of the research projects on the left.

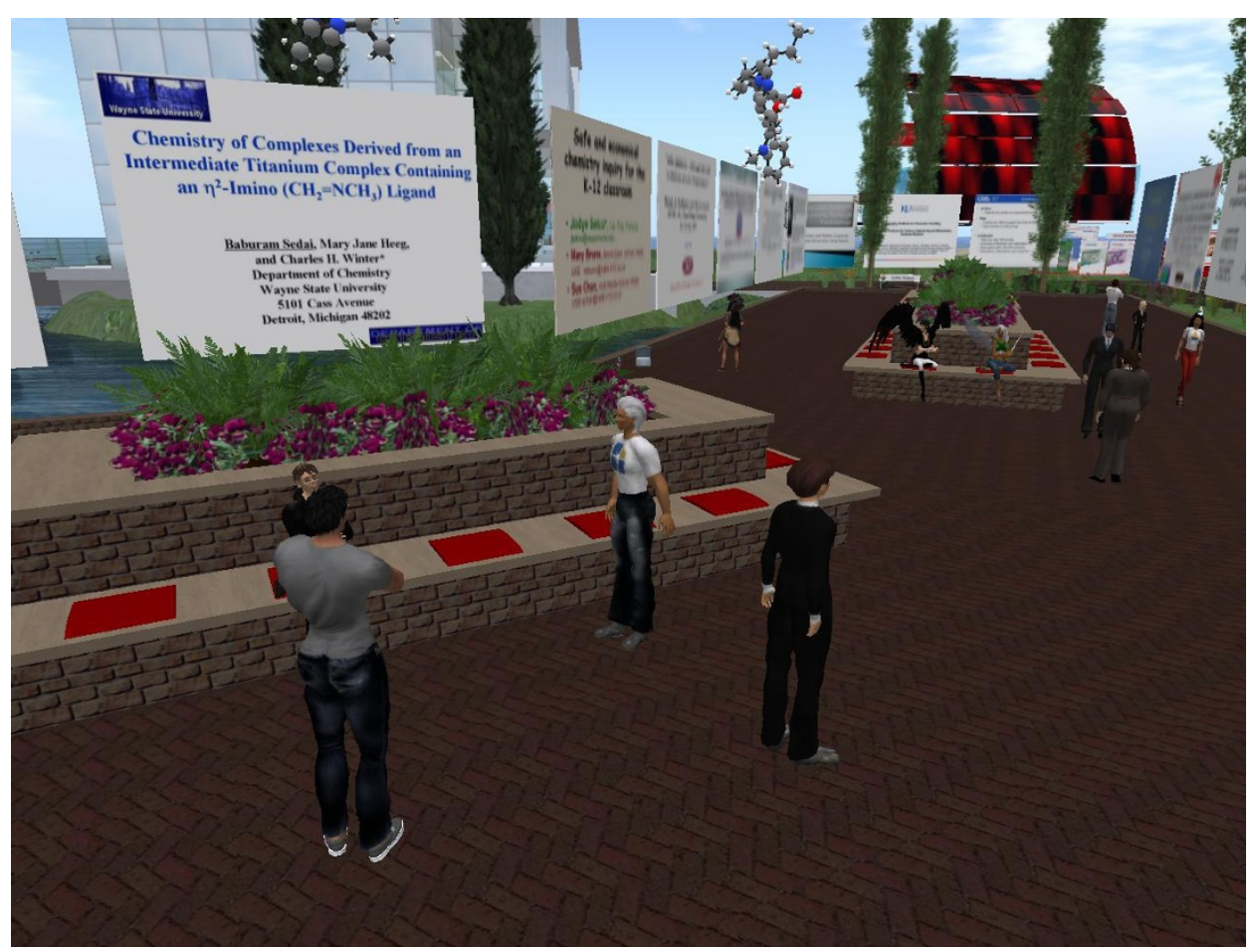

Figure 2 I

Virtual Sci-Mix on ACS Island. 


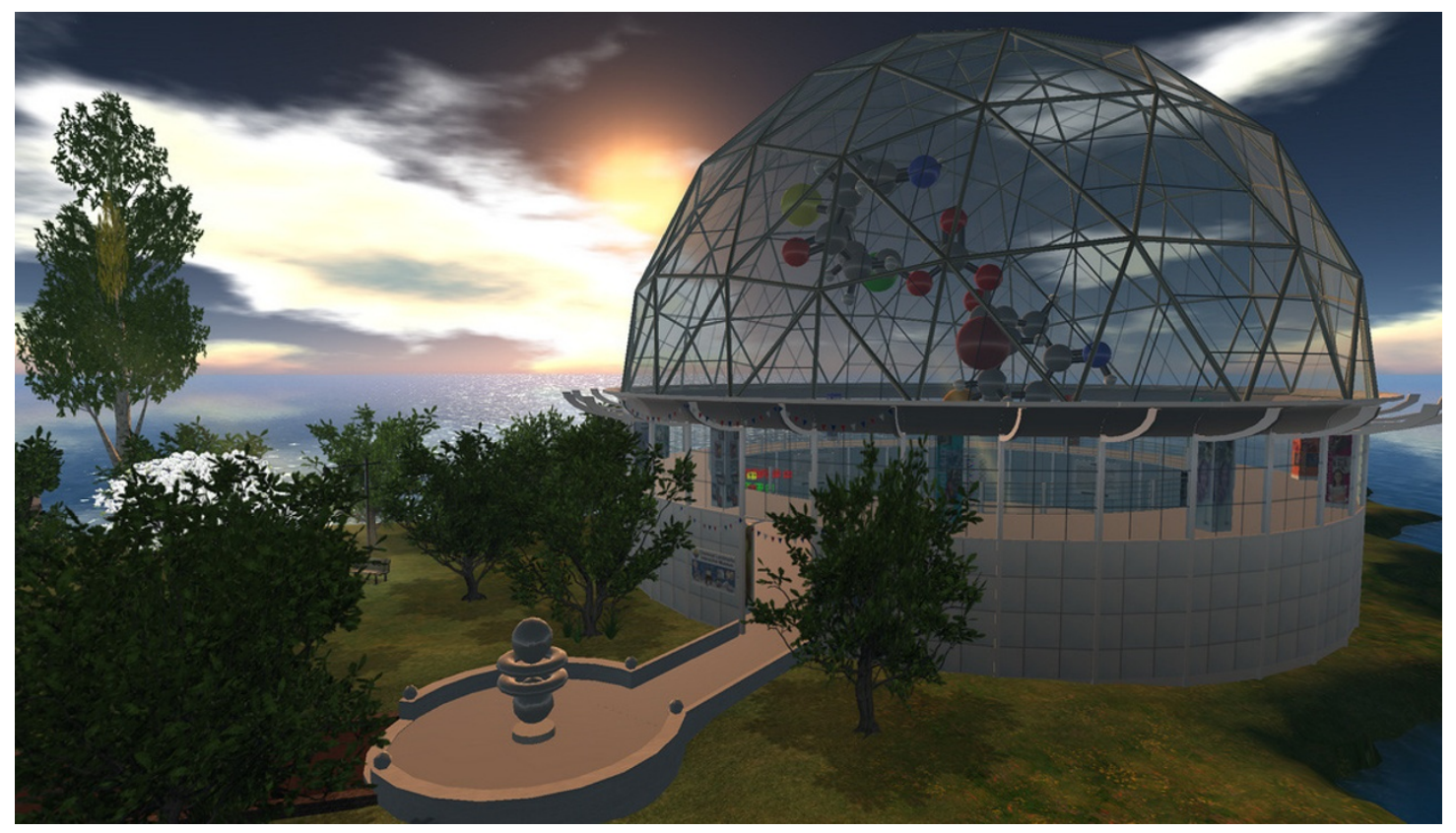

Figure 22

ACS Island's Interactive Chemical Landmarks Museum.

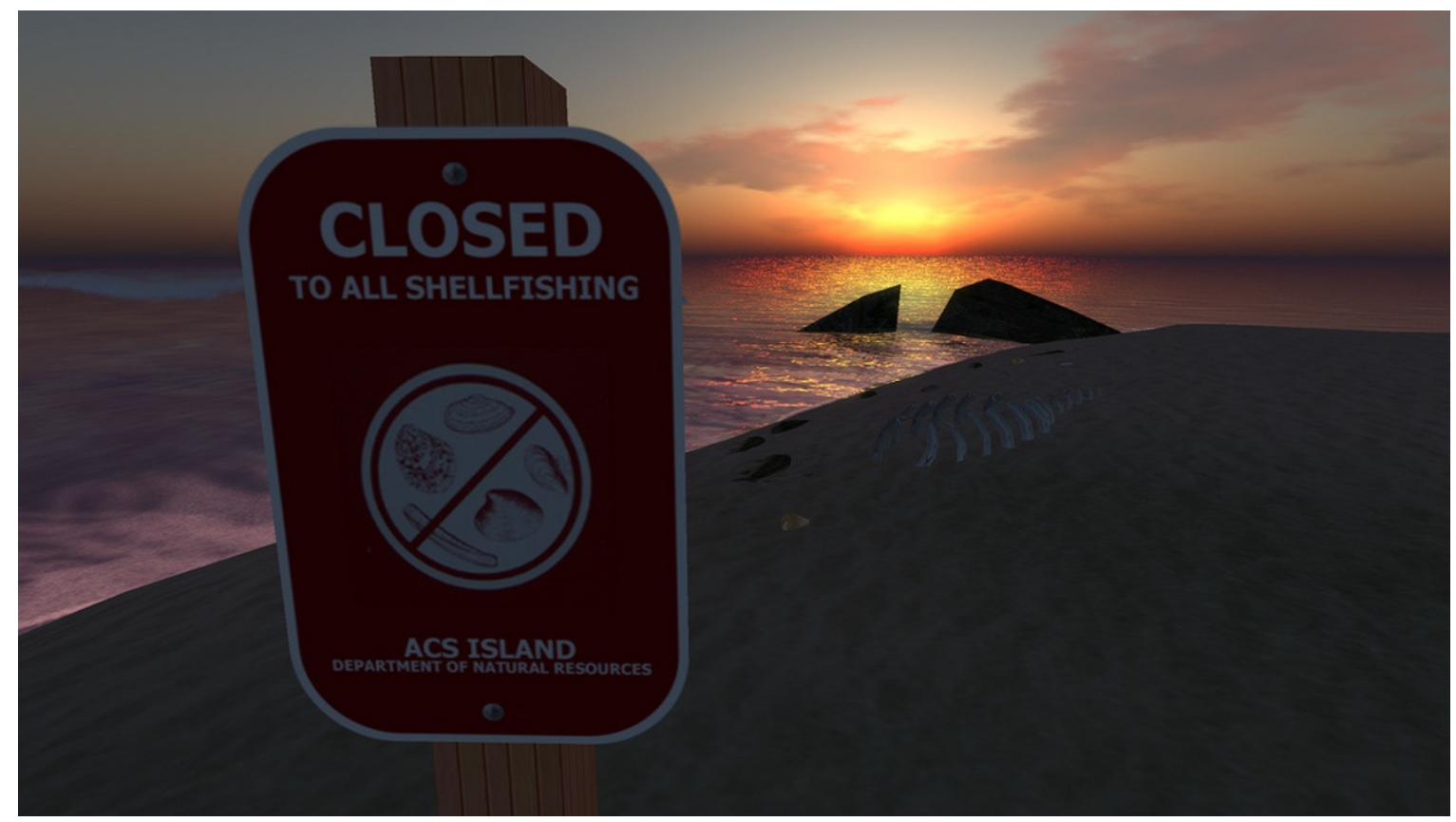

Figure 23

Red-Tide exhibit on ACS Island. 


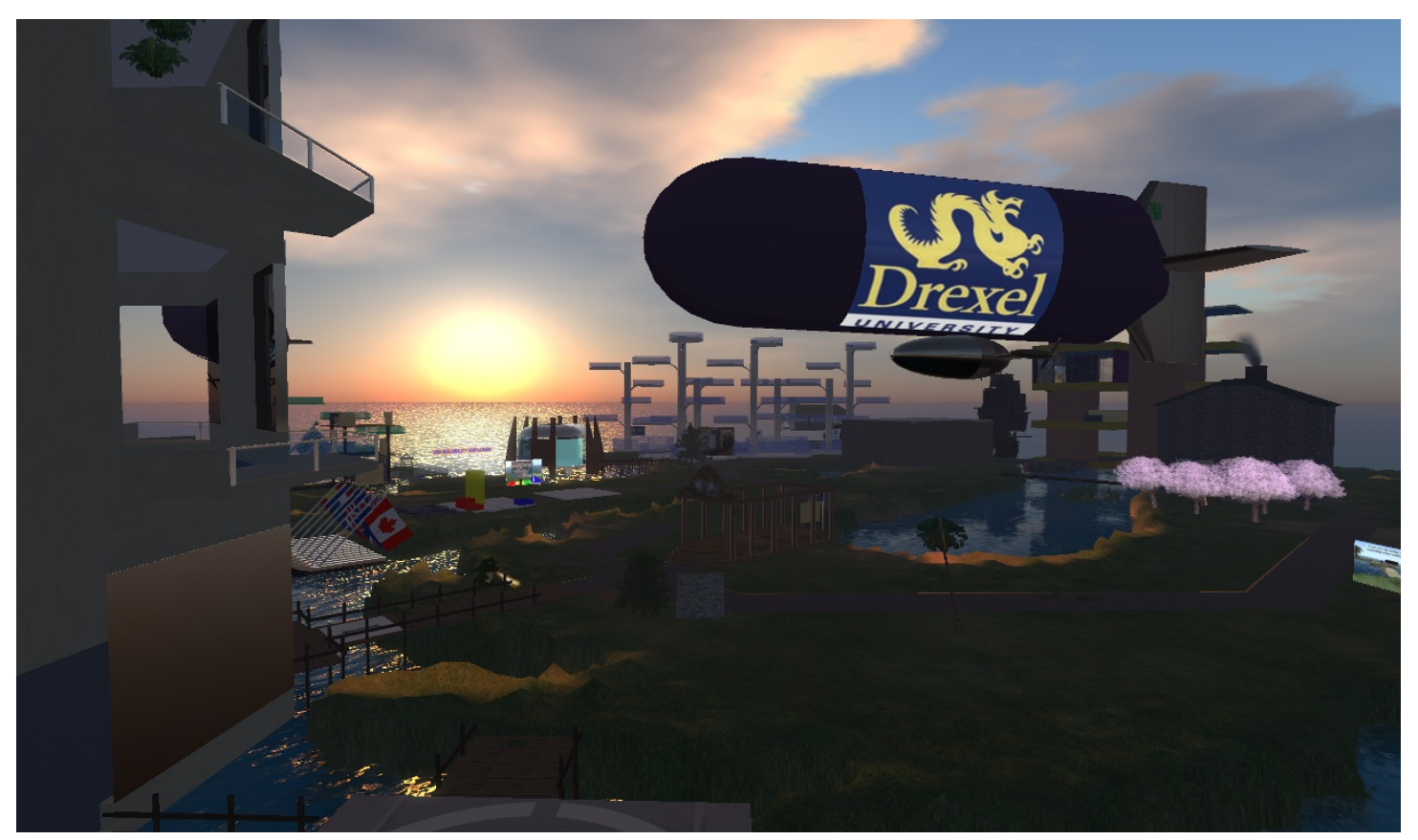

Figure 24

Drexel Island in Second Life.

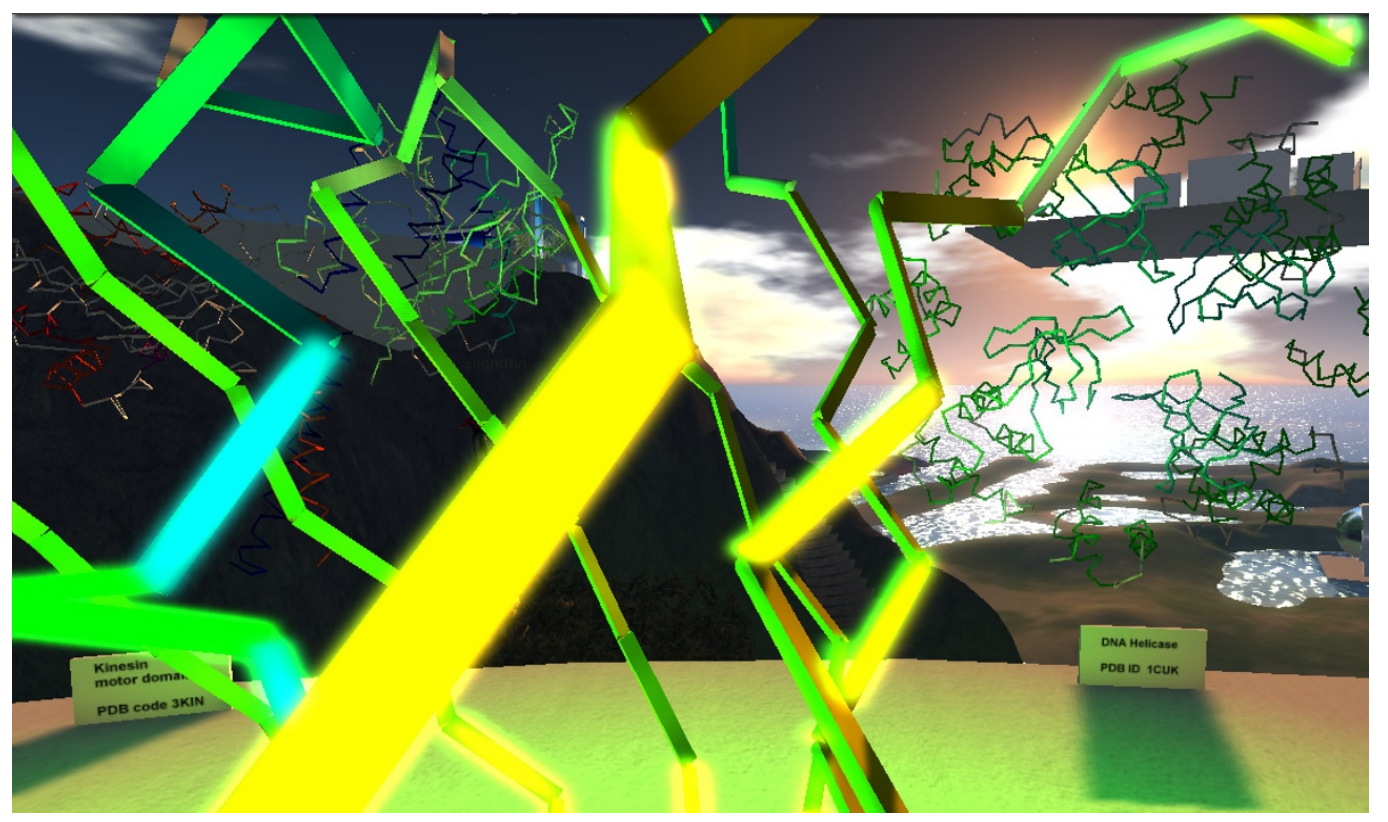

Figure 25

Interactive Protein Gallery. 
users communicate with each other via text (chat), voice, and gestures. Text entered into the chat window can be read not only by other users but also by 'listening' scripts within chat range. Orac - A freely available, Open Source, scripted tool that allows users to create conformally realistic molecules from SMILES strings in Second Life. The name Orac comes from a computer character in the British classic science fiction series Blakes 7. Prim - All items/ objects in Second Life are created with primitive objects (prims) such as cubes, sphere, cylinders, cones, etc. Rez, Rezzer, Rezzing - To Rez is a verb that means to create or to make an object appear in Second Life. Rezzing an object/prim can be done by dragging items from your inventory or by creating them in directly via the edit window. A scripted object that rezzes other objects, such as molecules, is called a rezzer. The term comes from the science-fiction movie Tron. Smi23d - smi23d is a cheminformatics web-service, originally written by Kevin Gilbert, improved upon by Rajarshi Guha, and is currently hosted by the cheminformatics group at Indiana University [50]. Sim - In Second Life a sim (simulation, more accurately region) is a named $256 \mathrm{~m}$ by $256 \mathrm{~m}$ area of land hosted by a single simulator process.

\section{Competing interests}

The authors declare that they have no competing interests.

\section{Authors' contributions}

JCB and ASIDL use Second Life to work collaboratively and together have created many of the chemistry related items in Second Life mentioned in this article. JCB led in the conception and use of the tools and ASIDL led in the tool creation and scripting.

\section{Acknowledgements}

The authors would like to thank Joanna Scott and Nature who provided the initial land in Second Life which led to the authors meeting and eventual collaboration, Kate Sellar and the American Chemical Society who provided the land where a number of the tools were created; Sandy Adam of Aldrich Chemical, Peter Miller of the University of Liverpool, David Reeves of Yeshiva University, Joan Slonczewski of Kenyon College, David Wild of Indiana University, Rajarshi Guha at the National Institutes of Health, Antony Williams of ChemSpider, Eloise Pasteur, and Beth Ritter-Guth who all contributed their time and expertise at various points during the author's collaboration.

\section{References}

I. Official Second Life statistics [https://blogs.secondlife.com/com munity/features/blog/2009/04/16/the-second-life-economy--firstquarter-2009-in-detail]

2. McConaghy T: Science Center Group. Second Life science center wiki [http://science-center-group.wikispaces.com].

3. Molecular Graphics Systems [http://en.wikipedia.org/wiki/ List of molecular graphics systems]

4. Herráez A: Biomolecules in the computer: Jmol to the rescue. Biochemistry and Molecular Biology Education 2006, 34(4):255-26I

5. Goodsell DS: Representing structural information with RasMol. Curr Protoc Bioinformatics 2005, Chapter 5(Unit 5.4):.
6. Kumar P, Zieglar A, Zieglar J, Uchanska-Ziegler B, Ziegler A: Grasping molecular structures through publication-integrated 3D models. Trends Biochem Sci 2008, 33(9):408-12.

7. Mol4D [http://wetche.cmbi.ru.nl//organic/]

8. Social Networking [http://en.wikipedia.org/wiki/ Social networking]

9. Bradley JC: InChI Rezzer in Second Life. [http://usefulchem.blog spot.com/2007/09/inchi-rezzer-in-second-life.html].

10. Simplified molecular input line entry specification [http:// en.wikipedia.org/wiki/

Simplified molecular input line entry specification]

II. International Chemical Identifier [http://en.wikipedia.org/wiki/ Inchi]

12. InChIKey [http://en.wikipedia.org/wiki/lnchi\#lnChIKey]

13. Bradley JC: Teaching Chemistry Mechanisms in Second Life. [http://drexel-coas-elearning.blogspot.com/2007/08/teaching-chemis try-mechansims-in-second.html].

14. Bradley JC, Rosenthal P, Guha R, Mirza K, Gut J: Open Notebook Science - Falcipain-2 Preliminary Results. Nature Precedings 2008 [http://dx.doi.org//0.1038/npre.2008.2216.1].

15. Bradley JC: Molecule Docking in Second Life. [http://use fulchem.blogspot.com $/ 2007 / 06 /$ molecule-docking-in-secondlife.html].

16. Subasi E, Basdogan C: A New Haptic Interaction and Visualization Approach for Rigid Molecular Docking. Virtual Environments Presence: Teleoperators \& Virtual Environments 2008, I7(I):73-90.

17. Ariantho D: Amino World. [http://daneelariantho.word press.com/2008/06/15/amino-world/].

18. Miller PGG, et al.: Protein Rezzing Toolkit. secondlifemolecules wiki [http://secondlifemolecules.wikispaces.com/proteins].

19. Protein Data Bank [http://www.pdb.org]

20. Greer J, Bush BL: Macromolecular Shape and Surface Maps by Solvent Extrusion. Proc Natl Acad Sci 1978, 75(I):303-307.

21. Monolith [http://secondlife.som.stonybrook.edu/monolith]

22. Bourke P: Evaluating Second Life As A Tool For Collaborative Scientific Visualization. Computer Games and Allied Technology 2008 conf 2008 [http://local.wasp.uwa.edu.au/ pbourke/papers/ cgat08/]

23. Bradley JC: NMR viewer in Second Life. [http://usefulchem.blog spot.com/2008/04/nmr-viewer-in-second-life.html]

24. Bradley JC, Mirza KB, Owens K, Osborne T, Williams Al: Optimization of the Ugi Reaction Using Parallel Synthesis and Automated Liquid Handling. J Vis Exp 2008:942.

25. Open Notebook Science Challenge [http://onschallenge.wikis paces.com]

26. Bradley JC: Interactive Visualization of ONS Solubility Data. [http://usefulchem.blogspot.com/2009/0I/interactive-visualization-ofons.html].

27. Edufrag project [http://edufrag.wikispaces.com]

28. Steinbeck C, Hoppe C, Kuhn S, Floris M, Guha R, Willighagen EL: Recent developments of the chemistry development kit (CDK) - an open-source java library for chemo- and bioinformatics. Current pharmaceutical design 2006, I 2:2 I I I-2220.

29. Bradley JC, Guha R, Lang ASID, Lindenbaum P, Neylon C, Williams A], Willighagen E: Chapter 16: Beautifying Data in the Real World from Beautiful Data. Edited by: Segaran T, Hammerbacher J. O'Reilly Media; 2009.

30. Bradley JC: Update on games and vodcast for orgo class. [http://drexel-coas-elearning.blogspot.com/2006/04/update-ongames-and-vodcast-for-orgo.html].

3I. Bradley JC: Spring 07 Post-Mortem. [http://drexel-coas-elearn ing.blogspot.com/2007/06/spring-07-post-mortem.html].

32. Bradley JC: The ChemTiles game. [http://usefulchem.blogs pot.com/2009/04/chemtiles-game.html].

33. Flickr group for ChemTiles [http://www.flickr.com/groups/ orgogame]

34. Bradley JC: Winter 09 term post-mortem: SpectralGame implementation. [http://drexel-coas-elearning.blogspot.com/ 2009/03/winter-09-term-post-mortem-spectralgame.html].

35. Bradley JC, Lancashire RJ, Lang ASID, Williams AJ: The Spectral Game: Leveraging Open Data and Crowdsourcing for Education. Journal of Cheminformatics 2009, I:9 [http://www.jchem inf.com/content/I/I/9] 
36. Bradley JC: Spring $\mathbf{2 0 0 8}$ post-mortem on organic chemistry courses. [http://drexel-coas-elearning.blogspot.com/2008/07/ spring-2008-post-mortem-on-organic.html].

37. Networking on Second Life and FriendFeed extra credit page [http://chem24l.wikispaces.com/extracredit]

38. Bradley JC: Virtual Poster Session on ACS Island. [http:// drexel-coas-elearning.blogspot.com/2008/02/virtual-poster-sessionon-acs-island.html].

39. Linden Lab: How Meeting In Second Life Transformed IBM's Technology Elite Into Virtual World Believers. [http://sec ondlifegrid.net.s3.amazonaws.com/docs/

Second Life Case IBM EN.pdf].

40. Nature Podcast [http://www.nature.com/nature/podcast]

41. SciFooLivesOn wiki [http://scifooliveson.wikispaces.com]

42. Second Nature Island [http://www.nature.com/secondnature]

43. Bradley JC, Lang ASID: Chemistry Concepts in Second Life. Presentation at the American Chemical Society meeting August 18, 2008 [http://drexel-coas-talks-mp3-podcast.blogspot.com/2008/08/chemis try-concept-in-second-life.html].

44. American Chemical Society Island SLurl [http://slurl.com/sec ondlife/ACS/87//57/25]

45. Sellar K: Welcome to ACS Island on Second Life. [http:// www.youtube.com/watch? $v=u K 5 a F f Q W c X Y]$.

46. Bradley JC: 3D periodic table in Second Life. [http://use fulchem.blogspot.com/2007//0/3d-periodic-table-in-secondlife.html].

47. Drexel Island wiki [http://drexelisland.wikispaces.com]

48. Elucian Islands Archipelago SLurl [http://slurl.com/secondlife/ Elucian\%20lslands/46/62/26]

49. Lang ASID, Kobilnyk DC: Visualizing Atomic Orbitals Using Second Life. Journal of Virtual Worlds Research 2009, 2(I): [https:// journals.tdl.org/jivwr/article/view/448/465].

50. Wild D: IU Cheminformatics Web Services find use in Second Life! 2009 [http://cheminfonews.blogspot.com/2009/07/iucheminformatics-web-services-find.html].

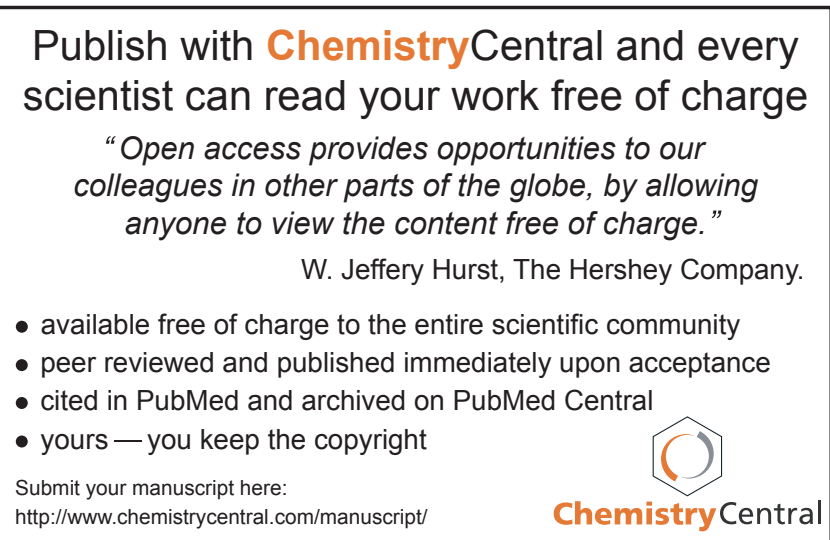

